\title{
Cilostazol Strengthens Barrier Integrity in Brain Endothelial Cells
}

\author{
Shoji Horai · Shinsuke Nakagawa · Kunihiko Tanaka · Yoichi Morofuji • \\ Pierre-Olivier Couraud • Maria A. Deli · Hiroki Ozawa • Masami Niwa
}

S. Horai · M. Ozawa

Department of Neuropsychiatry, Nagasaki University Graduate School of Biomedical Sciences, 1-7-1 Sakamoto, Nagasaki 852-8501, Japan

S. Nakagawa (ه)· K. Tanaka $\cdot$ Y. Morofuji $\cdot$ M. Niwa

Department of Pharmacology, Nagasaki University Graduate School of Biomedical Sciences, 1-12-4 Sakamoto, Nagasaki 852-8523, Japan

e-mail: shin3@nagasaki-u.ac.jp

S. Nakagawa $\cdot$ M. A. Deli $\cdot$ M. Niwa

BBB Laboratory, PharmaCo-Cell Company, Ltd., 1-43 Dejima, Nagasaki 850-0862, Japan

P. -O. Couraud

Inserm U1016 Institute Cochin, CNRS UMR8104, Université Paris Descartes, Sorbonne Paris Cité, 22 rue Méchain, 75014 Paris, France

\section{A. Deli}

Laboratory of Molecular Neurobiology, Institute of Biophysics, Biological Research Center, Hungarian Academy of Sciences, Temesvári körút 62, H-6726 Szeged, Hungary 
Abstract We studied the effect of cilostazol, a selective inhibitor of phosphodiesterase 3 (PDE3), on barrier functions of blood-brain barrier (BBB)-related endothelial cells, primary rat brain capillary endothelial cells (RBEC) and the immortalized human brain endothelial cell line hCMEC/D3. The pharmacological potency of cilostazol was also evaluated on ischemia-related BBB dysfunction using a triple co-culture $\mathrm{BBB}$ model $\left(\mathrm{BBB} \mathrm{Kit}^{\mathrm{TM}}\right.$ ) subjected to 6-h oxygen glucose deprivation (OGD) and 3-h reoxygenation. There was expression of phosphodiesterase 3B mRNA in RBEC, and a significant increase in intracellular cAMP content was detected in RBEC treated with both $1 \mu \mathrm{M}$ and $10 \mu \mathrm{M}$ cilostazol. Cilostazol increased the transendothelial electrical resistance (TEER), an index of barrier tightness of interendothelial tight junctions (TJs), and decreased the endothelial permeability of sodium fluorescein through the RBEC monolayer. The effects on these barrier functions were significantly reduced in the presence of protein kinase A inhibitor $\mathrm{H}$-89. Microscopic observation revealed smooth and even localization of occludin immunostaining at TJs and F-actin fibers at the cell borders in cilostazol-treated RBEC. In hCMEC/D3 cells treated with $1 \mu \mathrm{M}$ and $10 \mu \mathrm{M}$ cilostazol for $24 \mathrm{~h}$ and $96 \mathrm{~h}$, P-glycoprotein transporter activity was increased, as assessed by rhodamine 123 accumulation. Cilostazol improved the TEER in our triple co-culture BBB model with 6-h OGD/3-h reoxygenation. As cilostazol stabilized barrier integrity in BBB-related endothelial cells, probably via cAMP/PKA signaling, the possibility that cilostazol acts as a BBB-protective drug against cerebral ischemic insults to neurons has to be considered. 
Keywords Cilostazol · BBB-protective drug - Phosphodiesterase 3B - Blood-brain barrier · Tight junctions · Occludin · F-actin · P-glycoprotein · Oxygen glucose deprivation/reoxygenation · hCMEC/D3 cells · Brain endothelial cells (rat) 


\section{Introduction}

Neurons maintain function by overcoming neurotoxic endogenous and xenobiotic molecules, and pathological insults such as ischemic attacks on the neurovascular unit (NVU), an event closely related to blood-brain barrier (BBB) function (Abbott 2010; Zlokovic 2011). The BBB-related endothelial cells (brain endothelial cells) includes barrier integrity maintained by tight junctions (TJs), lack of pinocytes and fenestrae, and efflux pumps P-glycoprotein (ABCB1), a member of the ATP-binding cassette transporter family. Brain endothelial cells prohibit the passage of xenobiotics, blood-borne toxic substances and cells into the brain to protect neurons, in collaboration with neighboring cells, astrocytes and pericytes. Among the BBB apparatus, TJs form a complex structure of cell-cell adhesion molecules composed of integral membrane protein claudins (claudin-3, claudin-5 and claudin-12) and occludin, and cytoplasmic ZO-1 located at the cell border between brain endotheial cells that restricts the paracellular transport of water-soluble substances from the blood to the brain (Zlokovic 2011). P-glycoprotein expressed in the luminal and abluminal membranes of brain endothelial cells functions as an efflux pump to transport lipid-soluble molecules from brain endothelial cells and brain (Abbott et al. 2010). Therefore, damage to the BBB affects the onset and progress of neurological disorders with neuronal loss (Neuwelt et al. 2008). According to the neurovascular hypothesis, accumulation of amyloid- $\beta$ peptides in the brain during the development of Alzheimer's disease is a pathological phenomenon associated with BBB uptake of the peptides from the blood through the receptor for advanced end glycation products expressed in damaged brain endothelial cells (Mackic et al. 1998; Zlokovic 2011). Disruption of the BBB is 
responsible for neuronal loss and dysfunction in the time course after the onset of ischemic insults in cerebrovascular diseases. BBB breakdown with a disruption of TJs results in leakage of xenobiotics, blood-borne toxic substances and cells through paracellular transport and then triggers aberrant angiogenesis, vessel regression, brain hypoperfusion and inflammatory responses in the NVU resulting in the progression of cerebrovascular diseases with neuronal loss and dysfunction (Zlokovic 2011; Hermann and EIAIi 2012). Hence, with the recent understanding of the pathological significance of the NVU on neurological disorders, the BBB has become a new therapeutic target for saving neurons (Deli et al. 2010).

There is evidence to support the benefits of protecting against BBB disruption by stimulation of cyclic AMP (cAMP) signaling. In the last twenty years, studies proved that intracellular cAMP-elevation in brain endothelial cells increases barrier integrity (Rubin and Staddon 1991; Perrière et al. 2005; Deli et al. 2005). According to Maurice (2011), a molecular unit of cAMP/protein kinase A (PKA) and cAMP/EPAC1 packed with phosphodiesterase (PDE)4 exerts barrier-stabilizing effects on endothelial cells through adherens junctions (AJs). In addition to the influence on AJs, cAMP signaling also works on TJs of the BBB to increase the expression of claudin-5, a key protein of TJs, in a PKA-independent manner, and PKA activated by cAMP phosphorylates claudin-5 to strengthen barrier tightness (Ishizaki et al. 2003). Adrenomedullin, an endogenous cAMP-elevating ligand for G-protein coupled receptors linked to adenylyl cyclase, seems to constitutionally protect the BBB by targeting TJs in brain endothelial cells (Kis et al. 2001; Kis et al. 2006). Thus, cAMP signaling in brain endothelial cells seems pertinent to the protection of the BBB.

Among cAMP-elevating drugs interacting with molecules in cAMP signaling, 
cilostazol selectively inhibits PDE3, a cAMP-degrading enzyme, thus elevating intracellular cAMP content (Sudo et al. 2000). Although cilostazol is a remedy for the treatment of ischemic symptoms in patients with peripheral arterial obstruction (Thompson et al. 2002), the drug is also experimentally effective for neuroprotection against brain damage by cerebral ischemic insults (Choi et al. 2002; Hong et al. 2006; Watanabe et al. 2006; Lee et al. 2009). Thus, taken together with the recent clinical evidence on the long-term prevention of secondary stroke in patients with chronic ischemic stroke (Shinohara et al. 2010), cilostazol may act on the BBB as a BBB-protective drug. Hence, we studied here the effect of cilostazol on endothelial barrier integrity of TJs and P-glycoproteins in BBB-related endothelial cells, primary rat brain capillary endothelial cells (RBEC) (Morofuji et al. 2010) and the immortalized human brain endothelial cell line hCMEC/D3 (Weksler et al. 2005). The pharmacological potency of cilostazol on ischemia-related BBB dysfunction was also investigated using a triple co-culture BBB model (BBB Kit ${ }^{\mathrm{TM}}$ ) (Nakagawa et al. 2009) subjected to 6-h oxygen glucose deprivation (OGD) and 3-h reoxygenation.

\section{Materials and Methods}

Reagents and Animals

Cilostazol

(6-[4-(1-cyclohexyl-1H-tetrazol-5yl)butoxy]-3,4-dihydro-2-(1H)quinolinone, MW 369.46 Da) was kindly provided by Otsuka Pharmaceutical Co., Ltd., Tokushima, Japan. Cilostazol was dissolved to the concentration of $20 \mathrm{mM}$ in DMSO, stored at $-20{ }^{\circ} \mathrm{C}$ and diluted with the medium when the experiment was performed. All 
reagents and drugs were purchased from Sigma-Aldrich, USA, unless otherwise indicated.

Wistar rats were obtained from Japan SLC Inc., Japan. All animals were treated in strict accordance with the NIH Guide for Care and Use of Laboratory Animals (NIH Publication Nos. 80-23) and as approved by the Nagasaki University Animal Care Committee.

Cells

Primary cultures of RBEC

Primary cultures of RBEC were prepared from 3-week-old rats as previously described (Deli et al. 1997; Perrière et al. 2005; Nakagawa et al. 2007, 2009). Meninges were carefully removed from forebrains and gray matter was minced into small pieces of approximately $1 \mathrm{~mm}^{3}$ in ice-cold Dulbecco's modified Eagle’s medium (DMEM), then dissociated by 25 up-and-down strokes with a $5 \mathrm{ml}$ pipette in DMEM containing collagenase type 2 ( $1 \mathrm{mg} / \mathrm{ml}$, Worthington Biochemical Corp., USA), $300 \mu$ l DNase (15 $\mu \mathrm{g} / \mathrm{ml})$, and gentamycin $(50 \mu \mathrm{g} / \mathrm{ml})$, and then digested in a shaker for $1.5 \mathrm{~h}$ at $37^{\circ} \mathrm{C}$. The cell pellet was separated by centrifugation in $20 \%$ bovine serum albumin (BSA)-DMEM $(1,000 \times g, 20 \mathrm{~min})$. The microvessels obtained in the pellet were further digested with collagenase-dispase (1 mg/ml, Roche Applied Sciences, Switzerland) and DNase $\left(6.7 \mu \mathrm{g} / \mathrm{ml}\right.$ in DMEM for $45 \mathrm{~min}$ at $\left.37^{\circ} \mathrm{C}\right)$.

RBEC clusters were separated on a 33\% continuous Percoll (Pharmacia, Sweden) gradient, then collected and washed twice in DMEM before plating on 35-mm 
plastic dishes coated with collagen type IV $(0.1 \mathrm{mg} / \mathrm{ml})$ and fibronectin $(0.1 \mathrm{mg} / \mathrm{ml})$ (Day 0, Fig. 1). RBEC cultures were maintained in DMEM/F12 supplemented with 10\% fetal bovine plasma derived from serum (PDS) (Animal Technologies, Inc., USA), basic fibroblast growth factor (bFGF, Roche Applied Sciences, $1.5 \mathrm{ng} / \mathrm{ml}$ ), heparin (100 $\mu \mathrm{g} / \mathrm{ml})$, insulin $(5 \mu \mathrm{g} / \mathrm{ml})$, transferrin $(5 \mu \mathrm{g} / \mathrm{ml})$, sodium selenite $(5.0 \mathrm{ng} / \mathrm{ml})$ (insulin-transferrin-sodium selenite media supplement), gentamycin (50 $\mu \mathrm{g} / \mathrm{ml})$ and puromycin (4 $\mu \mathrm{g} / \mathrm{ml})\left(\mathrm{RBEC}\right.$ I medium) at $37^{\circ} \mathrm{C}$ with a humidified atmosphere of $5.0 \%$ $\mathrm{CO}_{2} / 95 \%$ air for 2 days. According to the findings of Perrière et al. (2005), in the first two days cells were incubated in medium containing puromycin $(4 \mu \mathrm{g} / \mathrm{ml})$ to avoid the contamination of pericytes. After 2 days, the cells received new medium containing all the components of RBEC medium except puromycin (RBEC II medium) (Day 2, Fig. 1a).

When the cultures reached $80 \%$ confluency (Day 4), the purified endothelial cells were passaged by brief treatment with trypsin $(0.05 \% \mathrm{w} / \mathrm{v})-$ EDTA $(0.02 \% \mathrm{w} / \mathrm{v})$ solution, and an in vitro BBB model with RBEC was constructed with Transwell ${ }^{\circledR}$ (Corning Incorporated Life Sciences, USA) inserts in 12-well culture plates (Nakagawa et al. 2007, 2009). Endothelial cells $\left(1.5 \times 10^{5}\right.$ cells $\left./ \mathrm{cm}^{2}\right)$ were seeded on the upper side of the collagen- and fibronectin-coated polyester membranes $(0.4 \mu \mathrm{m}$ pore size) of Transwell $^{\circledR}$ inserts. This in vitro BBB model was maintained in RBEC medium II for 1 day, and on the next day (Day 5) the medium was changed to RBEC medium II containing $500 \mathrm{nM}$ hydrocortisone (Hoheisel et al. 1998) (Day 5). Cilostazol was added to the luminal side of the BBB model at Day 5. Experiments with cilostazol were carried out on Day 8 or 9 (Fig. 1a). 
Human brain endothelial cell line hCMEC/D3

The immortalized human brain endothelial cell line hCMEC/D3 (Weksler et al. 2005) was originated from the stock of the Institute Cochin (CNRS UMR 8104-INSERM U567, Université René Descartes, Paris, France). hCMEC/D3 cells (5 × 10\% $/ \mathrm{cm}^{2}$, passage 32-35) were seeded in 24-well plates coated with $0.1 \mathrm{mg} / \mathrm{ml}$ collagen type IV, and were cultured in EBM-2 medium supplemented with EGM-2 MV SingleQuots (Lonza, Walkersville, MD) and $5 \% \mathrm{FBS}$ at $37^{\circ} \mathrm{C}$ in $5 \% \mathrm{CO}_{2}$. Experiments with rhodamine 123, a ligand of P-glycoprotein, were performed on Day 4 5 (Fig. 1b).

Detection of $r P D E 3 A$ and $r P D E 3 B$ mRNA in RBEC

For total RNA extraction, RBEC were cultured in 3.5-mm plastic dishes coated with collagen type IV and fibronectin. Total RNA was isolated with the RNeasy Mini Kit (Qiagen, Japan) according to the manufacturer's instructions. First strand cDNA was synthesized from $1.0 \mu \mathrm{g}$ of total RNA with the Reverse Transcription System (Promega, USA). Polymerase chain reaction (PCR) fragments for rPDE3A and rPDE3B were amplified using the primer pairs: sense primer 5'- CCG AAT TCC CTT ATC ATA ACA GAA TCC ACG CCA CT -3' and antisense primer 5'- GGA AAT TCG TGT TTC TTC AGG TCA GTA GCC -3’ for rPDE3A; sense primer 5’- CCG AAT TCT ATC ACA ATC GTG TGC ATG CCA CAG A -3’ antisense primer 5’- CCG AAT TCT TTG AGA TCT GTA GCA AGG ATT GC -3’ for rPDE3B (Cheng et al. 2004). PCR was performed in a final volume of $20 \mu$ containing $0.5 \mu 1$ of template cDNA, 1.6 $\mu l$ of dNTP mixture, $2 \mu$ of 10 x PCR buffer, 0.5 unit of TaKaRa Taq ${ }^{\mathrm{TM}}$ Hot Start 
Version polymerase (Takara Bio Inc, Japan) and $1 \mu \mathrm{M}$ of each primer using PCR Express II thermal cycler (Thermo Electron Corp, USA). PCR was performed with 30 cycles of denaturation at $98^{\circ} \mathrm{C}$ for $10 \mathrm{sec}$, annealing at $69^{\circ} \mathrm{C}$ for $30 \mathrm{sec}$ and extension at $72^{\circ} \mathrm{C}$ for 15 sec. The PCR products were analyzed by electrophoresis on $1.5 \%$ agarose gels and stained by ethidium bromide and visualized using FluorChem ${ }^{\mathrm{TM}}$ SP (Alpha Innotech, USA).

Measurements of Intracellular cAMP Concentration in RBEC

The Bridge-It cAMP designer fluorescence assay system (Mediomics LLC, USA) was used to measure cAMP levels in all samples (Kelley et al. 2007). RBEC were plated in 96-well plates at a density of $5 \times 10^{4}$ cells/well and allowed to grow attached to the bottom surface of the plate. After treatment with cilostazol at concentrations of $1 \mu \mathrm{M}$ and $10 \mu \mathrm{M}$ for $30 \mathrm{~min}$, cells were washed in buffered saline solution twice. Then, $100 \mu \mathrm{l}$ of Bridge cAMP assay solution was added and the plates were shaken for $30 \mathrm{~min}$ at room temperature. The intensity of fluorescence (excitation wavelength, $485 \mathrm{~nm}$; emission wave length, $535 \mathrm{~nm}$ ) was read with a fluorescence plate reader (Wallac 1420 ARVO Multilabel Counter, Perkin Elmer, USA). The concentration of cAMP was determined based on a standard curve. The amount of cAMP in the cell samples was standardized to the amount of protein in each sample as determined by the BCA protein assay kit (Thermo Scientific, USA).

Evaluation of TJ function in RBEC

To evaluate TJ function in RBEC treated with cilostazol, transendothelial electrical 
resistance (TEER), transendothelial permeability for sodium fluorescein (Na-F, MW $376 \mathrm{Da}$ ) and expressions of TJ proteins by immunocytochemistry were measured. TEER and transendothelial permeability coefficient $(\mathrm{Pe})$ calculated from the flux of small water-soluble inert tracers such as Na-F across the endothelial monolayer are straightforward methods to evaluate TJ function and BBB integrity (Deli et al. 2005).

\section{Measurement of TEER}

TEER, which reflects the flux of ions, in culture conditions mainly sodium ions through the cell layer, was measured using an EVOM resistance meter (World Precision Instruments, USA). RBEC cultured on Transwell ${ }^{\circledR}$ inserts in a 12-well plate and treated with cilostazol at increasing concentrations ranging from of $0.01 \mu \mathrm{M}$ to $10 \mu \mathrm{M}$ for $24 \mathrm{~h}$, $48 \mathrm{~h}, 72 \mathrm{~h}$ and $96 \mathrm{~h}$ were used to measure TEER. The resistance measurements of blank filters (background resistance) were subtracted from those filters with cells. The values are shown as $\Omega \times \mathrm{cm}^{2}$.

\section{Transendothelial Permeability for Na-F}

Na-F permeability through the RBEC monolayer, an index of paracellular transport across TJs, was determined as previously described (Nakagawa et al. 2009; Morofuji et al. 2010). Transwell ${ }^{\circledR}$ inserts with the cells treated with cilostazol for $96 \mathrm{~h}$ were transferred to 12-well plates containing $1.5 \mathrm{ml}$ assay buffer $(136 \mathrm{mM} \mathrm{NaCl}, 0.9 \mathrm{mM}$ $\mathrm{CaCl}_{2}, 0.5 \mathrm{mM} \mathrm{MgCl} 2,2.7 \mathrm{mM} \mathrm{KCl}, 1.5 \mathrm{mM} \mathrm{KH}_{2} \mathrm{PO}_{4}, 10 \mathrm{mM} \mathrm{NaH} \mathrm{PO}_{4}, 25 \mathrm{mM}$ glucose, and $10 \mathrm{mM}$ Hepes, $\mathrm{pH}$ 7.4) in the basolateral or lower compartments. In the inserts, the culture medium was replaced by $0.5 \mathrm{ml}$ buffer containing $10 \mu \mathrm{g} / \mathrm{ml} \mathrm{Na}-\mathrm{F}$. 
The inserts were transferred at $5 \mathrm{~min}, 15 \mathrm{~min}$, and $30 \mathrm{~min}$ to a new well containing assay buffer. The emission of Na-F was measured at $535 \mathrm{~nm}$ (excitation wavelength: $485 \mathrm{~nm}$ ). The permeability of Na-F was used as an index of paracellular transport (Deli et al. 2005; Nakagawa et al. 2007). The permeability coefficient Pe (cm/s) was calculated based on Fick’s Law (Youdim et al. 2003).

Immunocytochemical Detection of TJ Proteins and F-actin Fluorescent Cytochemistry

Seventy-two hours after treatment with $1 \mu \mathrm{M}$ cilostazol, TJ proteins claudin-5, occludin, and ZO-1 were examined immunocytochemically, according to a slight modification of our previous method (Nakagawa et al. 2009; Morofuji et al. 2010). After washing with phosphate-buffered saline (PBS) RBEC were fixed in $3 \%$ paraformaldehyde for 10 min and permeabilized with $0.1 \%$ Triton-X 100 for $10 \mathrm{~min}$. After washing with PBS and blocking with $3 \%$ bovine serum albumin (BSA) in PBS for $30 \mathrm{~min}$, samples were incubated for $30 \mathrm{~min}$ at $37^{\circ} \mathrm{C}$ with mouse monoclonal primary antibodies. All primary antibodies were used at a dilution of 1:100. After washing with PBS, as secondary antibodies Alexa Fluor 488-conjugated donkey anti-mouse immunoglobulins (Invitrogen Corporation, USA) were used at a dilution of 1:1000 for 30 min at $37^{\circ} \mathrm{C}$. To observe cytoskeletal F-actin networks, samples were incubated with Alexa Fluor ${ }^{\circledR} 546$ phalloidin (Invitrogen Corporation) at a dilution of 1:400 for $30 \mathrm{~min}$ at $37^{\circ} \mathrm{C}$. Preparations were mounted in Gel Mount (Biomeda, USA) and staining was examined by a Zeiss LSM5 Pascal Confocal laser scanning microscope (Carl Zeiss AG, Germany). 
In vitro Oxygen Glucose Deprivation (OGD) and Reoxygenation Studies on RBEC $\left(\mathrm{BBB} \mathrm{Kit}^{\mathrm{TM}}\right)$

We examined the effect of cilostazol on in vitro OGD and reoxygenation-induced $\mathrm{BBB}$ damage. Experiments were performed using $\mathrm{BBB} \mathrm{Kit}^{\mathrm{TM}}$ (RBE-12) (PharmaCo-Cell Ltd., Co., Nagasaki, Japan) composed of primary RBEC, rat astrocytes and rat pericytes (Nakagawa et al. 2009). Based on our preliminary experiments, we chose exposure times of $6 \mathrm{~h}$ for OGD and $3 \mathrm{~h}$ for reoxygenation (6-h OGD/3-h reoxygenation) were chosen (Fig. 2). In normoxia and 6-h OGD/3-h reoxygenation experiments, serum-free DMEM containing $4.5 \mathrm{~g} / \mathrm{L}$ glucose (glucose $^{+}$ DMEM) and serum- and glucose-free DMEM (glucose ${ }^{-}$DMEM) were added to the $\mathrm{BBB} \mathrm{Kit}^{\mathrm{TM}}$, respectively. Oxygen deprivation was generated using AnaeroPack $^{\mathrm{TM}}$ (Mitsubishi Gas Chemical Co., Inc., Japan). Reoxygenation was initiated by adding RBEC II medium after 6-h OGD. One $\mu \mathrm{M}$ cilostazol was added to the luminal (upper) compartment of the BBB Kit ${ }^{\mathrm{TM}}$ (RBE-12) after 6-h OGD. After 3-h reoxygenation in the presence or absence (OGD/reoxygenation control) of cilostazol, TEER was measured as described above.

Functional Assay for P-glycoprotein transporter in hCMEC/D3 cells

hCMEC/D3 cells have a similar morphology to primary human brain capillary endothelial cells and functionally express P-glycoprotein (Weksler et al. 2005; Poller et al. 2008). The functional activity of P-glycoprotein was determined by measuring the cellular accumulation of rhodamine 123, a ligand of P-glycoprotein (Fontaine et al. 
1996). hCMEC/D3 $\left(5 \times 10^{4} / \mathrm{cm}^{2}\right)$ were seeded to 24 -well plates. Cilostazol was added $6 \mathrm{~h}$, $12 \mathrm{~h}, 24 \mathrm{~h}$ and $96 \mathrm{~h}$ before the experiment (Fig. 1b). To examine the dose-dependency of the effect of cilostazol on P-glycoprotein, hCMEC/D3 cells were incubated for $24 \mathrm{~h}$ in the absence and presence of five different concentrations of cilostazol. The medium was removed and cells were washed twice with the assay buffer $(136 \mathrm{mM} \mathrm{NaCl}, 0.9 \mathrm{mM}$ $\mathrm{CaCl}_{2}, 0.5 \mathrm{mM} \mathrm{MgCl} 2,2.7 \mathrm{mM} \mathrm{KCl}, 1.5 \mathrm{mM} \mathrm{KH}{ }_{2} \mathrm{PO}_{4}, 10 \mathrm{mM} \mathrm{NaH} \mathrm{PO}_{4}, 25 \mathrm{mM}$ glucose, and $10 \mathrm{mM}$ Hepes, $\mathrm{pH}$ 7.4). Cells were incubated with $0.5 \mathrm{~mL}$ of assay buffer containing $5.0 \mu \mathrm{M}$ rhodamine 123 for $1 \mathrm{~h}$. To observe the effect of cAMP, we used H-89 (N-[2-((p-bromocinnamyl) amino) ethyl]-5-iso-quinoline sulfonamide, Calbiochem, USA), a specific PKA inhibitor (Hidaka and Kobayashi 1992). hCMEC/D3 cells were incubated for $24 \mathrm{~h}$ in the presence of $1.0 \mu \mathrm{M}$ cilostazol and/or H-89. Then, medium was removed and cells were washed twice with assay buffer. In another experiment, cilostazol or cyclosporine A, a substrate and inhibitor of P-glycoprotein, was added simultaneously with rhodamine 123 to investigate whether cilostazol is a P-glycoprotein substrate. Rhodamine 123 content was determined using a multiwell spectrofluorometer (excitation wavelength: $485 \mathrm{~nm}$, emission wavelength: $535 \mathrm{~nm}$ ). Cellular protein was measured by the BCA protein assay kit.

\section{Statistical Analysis}

All data are presented as mean \pm SEM. The values were compared using the analysis of variance followed by Bonferroni-Dunn test. Differences were considered statistically significant at $P<0.05$. 


\section{Results}

Firstly, we verified whether cilostazol targets RBEC (Fig. 3). We found expression of PDE3B mRNA in RBEC (Fig. 3a), but no significant expression of PDE3A mRNA. Our cAMP assay revealed that cilostazol increased the intracellular content of cAMP in RBEC (Fig. 3b). When RBEC were treated with cilostazol for 30 min at a concentration of $1 \mu \mathrm{M}$, a concentration equivalent to the blood serum level of $1.35 \sim 2.71 \mu \mathrm{M}$ (500 1,000 ng/ml) clinically detected in patients (Kajinami et al. 2000), an approximately 1.5-times higher amount of intracellular cAMP (55 $\pm 6 \mathrm{pmol} / \mathrm{mg}$ protein, $\mathrm{n}=10)$ was observed, as compared with the level in the control (36 $\pm 3 \mathrm{pmol} / \mathrm{mg}$ protein, $\mathrm{n}=11$ ). At $10 \mu \mathrm{M}$, cilostazol also significantly elevated cAMP content 1.8 -fold (61 $\pm 6 \mathrm{pmol} / \mathrm{mg}$ protein, $\mathrm{n}=9$ ). Thus, we found that cilostazol stimulated RBEC to increase intracellular cAMP.

Next the effect of cilostazol on interendothelial TJ function was examined by measuring TEER, transendothelial permeability for Na-F, and expression of TJ proteins (Fig. 4). The RBEC monolayer used here had a high level of TEER, as detected at the experimental time-point of $96 \mathrm{~h}$ (control value at $96 \mathrm{~h}$ : $196 \pm 26 \Omega \times \mathrm{cm}^{2}, \mathrm{n}=13$ ).

At concentrations of $1 \mu \mathrm{M}$ and $10 \mu \mathrm{M}$, cilostazol strengthened TJ function in RBEC. A significantly higher TEER was detected when RBEC were treated with $1 \mu \mathrm{M}$ cilostazol for 24 h, and a time-dependent elevation was observed between 24 h, 48 h, 72 h and $96 \mathrm{~h}$ treatments of $1 \mu \mathrm{M}$ and $10 \mu \mathrm{M}$ cilostazol (Fig. 4a). The strongest effect of cilostazol on TEER was observed at 96-h treatment of $1 \mu \mathrm{M}$ cilostazol (control TEER value: $196 \pm 26 \Omega \times \mathrm{cm}^{2}$ vs. $1 \mu \mathrm{M}$ cilostazol: $\left.321 \pm 30 \Omega \times \mathrm{cm}^{2}, \mathrm{n}=13, P<0.01\right)$. There was no significant difference between TEER elevation with $1 \mu \mathrm{M}$ and $10 \mu \mathrm{M}$ 
cilostazol.

Cilosatzol also changed the paracellular permeability for Na-F, a small water-soluble fluorescein marker, across TJs of the RBEC monolayer at 96-h treatment (Fig. 4b). A significant decrease in Na-F permeability in RBEC treated with cilostazol at concentrations of $1 \mu \mathrm{M}$ and $10 \mu \mathrm{M}$ for $96 \mathrm{~h}$ (control Pe value: $4.70 \pm 0.44 \times 10^{-6} \mathrm{~cm} / \mathrm{s}$ vs. $1 \mu \mathrm{M}$ cilostazol: $2.60 \pm 0.61 \times 10^{-6} \mathrm{~cm} / \mathrm{s}$, and vs. $10 \mu \mathrm{M}$ cilostazol: $2.48 \pm 0.40 \times 10^{-6}$ $\mathrm{cm} / \mathrm{s}, \mathrm{n}=12, P<0.01)$. Also, no significant difference in Na-F permeability was detected between RBEC treated with $1 \mu \mathrm{M}$ and $10 \mu \mathrm{M}$ cilostazol. These data indicates that cilostazol strengthens paracellular barrier in RBEC.

To investigate which downstream effector of cAMP is operative in the effect of cilosztazol on TJs of RBEC, we used H-89, a specific PKA inhibitor of H-89 (Hidaka and Kobayashi 1992). As shown in Fig. 5, H-89 completely blocked the effect of cilostazol on TEER. No changes in TEER were observed in RBEC when the cells were simultaneously treated with $1 \mu \mathrm{M}$ cilostazol and $5 \mu \mathrm{M}$ H-89 for $96 \mathrm{~h}$ (Fig. 5a). Consistent with the data on TEER, H-89 diminished cilostazol-induced tightness of paracellular barrier, as evidenced by the lack of decrease in NaF-permeability of cilostazol-treated RBEC (Fig. 5b). Thus, cilostazol-induced tightness of brain endothelial barrier seems to depend on cAMP/PKA signaling.

Consistent with cilostazol-induced elevation of TEER, our immunocytochemical study revealed continuous and linear staining of the TJ proteins claudin-5, ZO-1 and occludin, marginally localized along the cell border of RBEC treated with cilostazol at $1 \mu \mathrm{M}$ for $72 \mathrm{~h}$ (Fig. 6). Microscopic observation revealed that there was no significant difference in morphological distribution and fluorescence intensity of claudin-5 (Fig. 6 a, b) and ZO-1 (Fig. 6 e, f) between cilostazol-treated 
RBEC and control cells. However, as indicated in the boxes in Fig. 6c, a continuous, smooth, pericellular and belt-shaped pattern of occludin immunostaining was noted in RBEC treated with $1 \mu \mathrm{M}$ cilostazol for $96 \mathrm{~h}$ (Fig. 6c), as compared with the "zipper-like" and "prickly-leaf" irregularities seen in the control cells (Fig. 6d). Among the TJ proteins examined here, changes in the localization of occludin at the cell border in cilostazol-treated RBEC were the most pronounced.

Cilostazol also exerted an effect of cytoskeletal F-actin networks. In the control RBEC monolayers there were numerous cytoplasmic actin stress fibers revealed by F-actin staining (Fig. 6h). On the contrary, stress fibers became less numerous and a strict localization of F-actin bundles at the cell border was noted in cilostazol-treated RBEC (Fig. 6g, boxed areas). Similarly to the case of occludin immunostaining, our cytochemical technique revealed that cilostazol increased the localization of cytoskeletal F-actin fibers at the cell border.

We further investigated the effect of cilostazol on an in vitro BBB model (Fig. 7). As shown in Fig. 2, BBB Kit ${ }^{\mathrm{TM}}$ (PharmaCo-Cell Company Ltd., Japan), a co-culture model constructed from three types of BBB-related cells: primary RBEC, rat pericytes and rat astrocytes (Nakagawa et al. 2007, 2009) was subjected to 6-h OGD/3-h reoxygenation to mimic transient cerebral ischemia and reperfusion in vitro (Ceruti et al. 2012). At the start of experiments, TEER values of BBB Kit ${ }^{\mathrm{TM}}$ (RBE-12) used here were $186 \pm 16 \Omega \times \mathrm{cm}^{2}$ (normoxia experiment, $\mathrm{n}=8$ ) and $188 \pm 13 \Omega \times \mathrm{cm}^{2}(\mathrm{OGD}$ experiment, $\mathrm{n}=8$ ), respectively. After $6 \mathrm{~h}$, TEER of BBB Kit ${ }^{\mathrm{TM}}$ with 6-h OGD was reduced to the level of $38 \pm 2 \Omega \times \mathrm{cm}^{2}$ ( $\mathrm{n}=8$ ). We also observed the reduction in TEER of the control BBB Kit ${ }^{\mathrm{TM}}$ used in normoxia experiments $\left(93 \pm 9 \Omega \times \mathrm{cm}^{2}, \mathrm{n}=8\right)$. As the same phenomenon was previously reported by Nitz et al. (2003), we thought that the 
reduction was due to the medium change in culture that in normoxia experiments we changed the medium the BBB Kit medium containing $10 \%(\mathrm{v} / \mathrm{v})$ PDS to serum-free DEMN containing $4.5 \mathrm{~g} / \mathrm{dl}$ glucose (glucose ${ }^{+}$DMEM).

After 6 h of OGD/normoxia and 3 h of reoxygenation experiments (Fig. 2), in normoxia control experiments where RBEC in BBB Kit ${ }^{\mathrm{TM}}$ were treated with $1 \mu \mathrm{M}$ cilostazol for $3 \mathrm{~h}$, we found that cilostazol elevated TEER to 127\% (106 $\pm 16 \Omega \times \mathrm{cm}^{2}$, $\mathrm{n}=8$ ) of the control (84 $\pm 14 \Omega \times \mathrm{cm}^{2}, \mathrm{n}=8$ ) (Fig. 7). The barrier integrity of RBEC in the kit was damaged by 6-h OGD/3-h reoxygenation, as deduced from the finding that TEER was decreased to 50\% of the OGD/reoxygenation control level (hypoxia control: $39 \pm 7 \Omega \times \mathrm{cm}^{2}, \mathrm{n}=7$ ). Treatment with $1.0 \mu \mathrm{M}$ cilostazol during the period of 3 -h reoxygenation after 6-h OGD led to a significant recovery of TEER up to $66 \pm 9 \Omega \times$ $\mathrm{cm}^{2}$ (n=7, $P<0.05$ vs. the 6-h OGD/3-h reoxygenation control). Thus, cilostazol reduced OGD/ reoxygenation-induced impairment in barrier integrity of RBEC in the $\mathrm{BBB} \mathrm{Kit}^{\mathrm{TM}}$.

In addition to TJ function, we further investigated the effect of cilostazol on the efflux pump, another important element of the BBB. The immortalized human brain endothelial cell line hCMEC/D3 was used as a model of human BBB cells with the functional expression of human type of P-glycoprotein (Tai et al. 2009; Carl et al. 2010; Chan et al. 2011). Taking the high-lipophilicity of cilostazol into account, we examined whether cilostazol directly binds to P-glycoprotein as a P-glycoprotein transporter substrate such as cyclosporine A (Fig. 8). P-glycoprotein transporter function was assessed by the method of rhodamine 123 accumulation, a ligand of P-glycoprotein (Fontaine et al. 1996). Cyclosporin A (CsA), an inhibitory substrate of P-glycoprotein used as a reference standard (Balts et al. 2007), induced accumulation of rhodamine 123 
in hCMEC/D3 cells when given simultaneously with the dye at a concentration of 10 $\mu \mathrm{M}$ for $1 \mathrm{~h}$, whereas cilostazol $(10 \mu \mathrm{M})$ did not affect the cellular content of rhodamine 123 (Fig. 8), indicating that this lipophilic drug is not a P-glycoprotein substrate capable of binding directly to the protein.

As shown in Fig. 9, we found that cilostazol worked on hCMEC/D3 cells to increase P-glyprotein transporter function. One-hour accumulation of rhodamine 123 was significantly reduced in hCMEC/D3 cells treated with $1 \mu \mathrm{M}$ cilostazol at both $24 \mathrm{~h}$ and $96 \mathrm{~h}$, prior to rhodamine 123 assay (Fig. 9a). No changes were observed in the cells treated for $6 \mathrm{~h}$ and $12 \mathrm{~h}$. The P-glycoprotein transporter function of hCMEC/D3 cells was strengthened when these cells were treated with cilostazol at a concentration of 1 $\mu \mathrm{M}$ for $24 \mathrm{~h}$ and $96 \mathrm{~h}$. Cilostazol-induced enhancement of P-glycoprotein function depended on the duration of treatment with cilostazol. Also, we examined the dose-dependent effect of cilostazol on P-glycoprotein transporter function (Fig. 9b). When the cells were treated with increasing concentrations ranging from $0.01 \mu \mathrm{M}$ to 10 $\mu \mathrm{M}$ for $24 \mathrm{~h}$, cilostazol acted on P-glycoprotein transporter function in hCMEC/D3 cells dose-dependently. Thus, a cilostazol-induced increase of P-glycoprotein transporter function was evident in hCMEC/D3 cells.

As shown in Fig. 10, H-89 completely blocked cilostazol-induced reduction in rhodamine 123 accumulation in hCMEC/D3 cells, when cells were treated with $1 \mu \mathrm{M}$ cilostazol in the presence of H-89 $(5 \mu \mathrm{M})$ for $24 \mathrm{~h}$. H-89 alone exerted no change on rhodamine 123 accumulation in hCMEC/D3 cells. From this, the effect of cilostazol on P-glycoprotein seems to depend on cAMP/PKA signaling.

\section{Discussion}


The BBB protects neurons against xenobiotic, neurotoxic and vasculotoxic molecules in the blood as a main constituent of the NVU (Zlokovic 2011). As neurons survive in rats treated with cilostazol after brain damage from delayed neuronal death with transient forebrain ischemia (Lee et al. 2009) and chronic cerebral hypoperfusion (Watanabe et al. 2006), our present finding that cilostazol possibly acts on the BBB sheds light on the potential for development of BBB-protective drugs for neuroprotection across the pharmacological spectrum of PDE3B inhibition.

PDE Expression and cAMP Signaling in Vascular Endothelial Cells

Based on accumulated evidence, including the pharmacological spectrum of cilostazol on platelets, cardiocytes and vascular myocytes as a PDE3A inhibitor, PDE3A and PDE3B have been thought to be operative within cells implicated in peripheral cardiovascular function, fertility and lipolysis (Lugnier 2006; Omori and Kotera 2007). In fact, PDE3B was found to be abundantly expressed in human adipose tissue (Reinhardt et al. 1995), rat white and brown adipose tissue, and hepatocytes (Miki et al. 1996). Netherton and Maurice (2005) found that both PDE3A and PDE3B are co-expressed in bovine aortic endothelial cells, while only PDE3A is found in human umbilical vein endothelial cells, a finding that indicates heterogeneous expression of the PDE3 subfamily of proteins in vascular endothelial cells. Among members of the PDE family, PDE4 has been found to be predominantly present in the peripheral endothelial cells of the vascular system (Lugnier 2006; Omori and Kotera 2007; Cheng et al. 2010). In the present study, selective expression of PDE3B mRNA and 
cilostazol-induced elevation in intracellular cAMP levels became evident in RBEC. Our data are on agreement with the finding of Schankin et al. (2010) that there is significant expression of PDE3B in immortalized human brain microvascular endothelial cells. Considering the findings of Sudo et al. (2000) that cilostazol inhibits recombinant human PDE3A, rat PDE3B and rat PDE4 with IC50 values of $0.2 \mu \mathrm{M}, 0.38 \mu \mathrm{M}$ and 88 $\mu \mathrm{M}$, respectively, it would appear true that the increase in cAMP levels induced by 1 $\mu \mathrm{M}$ and $10 \mu \mathrm{M}$ cilostazol seen in the current study is due to inhibition of PDE3B activity.

Lorenowicz et al. (2008) found that activation of protein kinase A (PKA) and exchange protein directly activated by cAMP1 (EPAC1), both downstream effectors of cAMP, protected barrier integrity in the peripheral vascular endothelial cells. They also demonstrated, that cAMP/PKA and cAMP/EPAC1 signaling independently function on barrier integrity in human umbilical vein endothelial cells. Recently, Maurice (2011) introduced a new paradigm for compartmentalized cAMP signaling in vascular endothelial cells. A functional unit composed of a molecular unit of PDE3B- and PDE4D-tethered exchange protein activated by cAMP1 (EPAC1) is proposed to work as one 'signalosome' in an intracellular line of PI3K $\gamma$-encoded signals to regulate angiogenesis functionally linked to integrin-dependent vascular endothelial cell adhesion and endothelial barrier tightness. In collaboration with cAMP/PKA signaling, PDE3B/EPAC1- and PDE4/EPAC1-based cAMP-signalosomes contribute to increase the barrier stability of vascular endothelial cells. In peripheral human arterial endothelial cells (HAEC), PDE4D/EPAC1-based cAMP-signalosome preferentially stimulates barrier integrity to reduce HAEC permeability (Rampersad et al. 2010), whereas PDE3B/EPAC1-based cAMP-signalosome works on integrin-related vascular 
endothelial adhesion and tubule formation during angiogenesis (Wilson et al. 2011). Lee et al. (2011) found that cilostazol stimulated integrin $\beta 1$ expression, closely associated with endothelial cell adhesion in the vascular beds of mice brain, through activation of both PKA and EPAC1 signals. Although no data on the influence of cilostazol on the interaction between EPAC1 and PED3B was provided in this study, as we found evidence that cilostazol acts as a PDE3B inhibitor to induce barrier tightness in RBEC, the possibility that there is a different mechanism in PDE3B/EPAC1- and PDE4/EPAC1-based cAMP-signalosomes between peripheral and brain endothelial cells may have to be considered.

Cilostazol acts directly on RBEC to increase intracellular cAMP in vitro as a PDE inhibitor, similarly to agonists for G protein-coupled receptor which stimulate adenylyl cyclases responsible for production of cAMP. Accumulation of cAMP in RBEC is also increased by an autocrine peptide, adrenomedullin, constitutionally produced in brain endothelial cells (Kis et al. 2006) and linked to G protein-coupled receptor-mediated activation of adenylyl cyclases. Since adrenomedullin stabilizes barrier characteristics through a TJ-strengthening effect (Kis et al. 2001; Chen et al. 2006), studies to elucidate the pharmacological participation of cilostazol in adrenomedullin-mediated autocrine regulation of the BBB would be of interest.

Effect of Cilostazol on Barrier Function of brain endothelial cells

TEER and paracellular permeability are two fundamental parameters of the quality of the barrier made by brain capillary endothelial cells (Deli et al. 2005). We observed here that cilostazol worked on RBEC to elevate TEER and decrease permeability at clinically 
relevant doses doses of 0.01 10 $\mu \mathrm{M}$ (Kajinami et al. 2000). Similar effects of cilostazol were observed in cultured human brain endothelial cells at a higher dose of $30 \mu \mathrm{M}$ (Liu et al . 2012). As this effect was inhibited by H-89, a PKA isomerase type II (PKA-RII) inhibitor, it seems likely that PKA-RII was preferentially chosen as a target molecule of cAMP elevated by an inhibition of PDE3B by cilostazol in a cAMP-signaling compartment of RBEC, among three downstream effectors of PKA, EPAC1 and cyclic nucleotide-gated (CNG) channels. Recent progress on the compartmentalized cAMP/PKA signaling in vascular endothelial cells revealed that in pulmonary microvascular endothelial cells, PKA-RII activated by plasmalemmal cAMP distinctly produced in a cellular compartment of the plasma membrane signals enhanced barrier function through an organization of cell adhesion molecules and cytoskeletal F-actin networks. Conversely, cytosolic cAMP stimulates PKA-RI in a cytosol compartment to disrupt barrier integrity, a phenomenon related to endothelial microtubule dynamics (Sayner et al. 2011; Feinstein et al. 2012). As PKA-RII is anchored to A-kinase anchoring proteins (AKAP) bound to the plasma membrane (Zaccolo 2011; Di Benedetto et al. 2008), it may be that there is an increase of cAMP in a compartment at the plasma membrane of RBEC treated with cilostazol, and that the plasmalemmal cAMP then acts on PKA-RII to strengthen barrier integrity.

TEER directly reflects the tightness of cell adhesion to basal membrane and cell-to-cell contacts made by adherens junctions and TJs, and regulated by cell adhesion molecules and cytoskeletal F-actin networks (Taddei et al. 2008; Carman et al. 2011). In the case of brain capillary endothelial cells, the anatomical basis of the BBB, TJs are the main determinant of TEER (Abbott et al. 2010). Analysis of immunostaining for claudin-5, occludin and ZO-1, proteins functionally organizing TJs revealed that 
cilostazol improved the morphological pattern of occludin in cilostazol-treated RBEC. This histological improvement in occludin immunostaining may results from an increased amount of occluding in cilostazol-treated RBEC (Carman et al. 2011), or changes in the proportion of de novo phosphorylated occludin in TJs (Nishitsuji et al. 2011; Yamamoto et al. 2008). Taken together with the previous findings that claudin-5 expressed in TJs is thought to be closely related to the tightness of BBB integrity with a high TEER (Nitta et al. 2003; Furuse et al. 2006; Koto et al. 2007; Tsukita et al. 2008), the present observation of high sTEER and an improvement in occludin organization in TJs of RBEC treated with cilostazol without changes in claudin-5 is noteworthy. However, Carman et al. (2011) recently reported that simultaneous activation of adenosine receptor $A_{1}$ and $A_{2 A}$ significantly reduced occludin expression and TEER in primary mouse brain endothelial cells, with minor effects on claudin-5 and ZO-1 expression in TJs. Furthermore, according to Yamamoto et al. (2008), occludin is phosphorylated at T382 and S507 by the activation of RhoA/Rho kinase, and phosphorylated occludin has been linked to the reduction in barrier tightness with a low TEER in immortalized mouse brain microvascular endothelial cells. As cAMP/PKA signaling inhibits RhoA/Rho kinase through its downstream effector Rac1, a Ras-related GTPase (Spindler et al. 2010; Becker et al. 2010), cAMP-mediated PKA/Rac 1 activation may decrease the proportion of phosphorylated occludin and increase barrier integrity with a high TEER in cilostazol-treated RBEC.

In contrast to occludin phosphorylation via activation of RhoA/Rho kinase, PKC-induced phosphorylation of occludin strengthens barrier integrity via TJs in MDCK epithelial cells and in primary mouse brain endothelial cells (Suzuki et al. 2009; Nishitsuji et al. 2011). Phosphorylation of occludin at tyrosine residues by c-Src can 
also reduces TJ function by preventing its binding to ZO-1 (Elias et al. 2009). Thus, as various types of phosphorylated occludin seem to exert opposing effects on barrier integrity and $\mathrm{TJ}$ function, mechanisms by which phosphorylated occludin participates in barrier tightness and strong $\mathrm{TJ}$ function in cilostazol-treated RBEC remain to be elucidated.

Claudin-5 in TJs is phosphorylated in a cAMP/PKA signaling-dependent manner to increase $\mathrm{TJ}$ function and a tight barrier in primary porcine brain endothelial cells (Soma et al. 2004). On the contrary, in immortalized mouse brain capillary endothelial cells, claudin-5 (T207) phosphorylated by RhoA/Rho kinase functions in TJs to reduce barrier tightness (Yamamoto et al. 2008). Furthermore, oxidative stress induces tyrosine-phosphorylation of claudin-5 in TJs resulting in a low TEER in primary human brain microvascular endothelial cells (Haorah et al. (2007). ZO-1 is also phosphorylated by Vibrio cholera-derived zonular occludin toxin, and phsophorylated ZO-1 disengages from occludin to open TJs in rat intestinal IEC6 cells (Goldblum et al. 2011). Although the present study revealed no significant changes in claudin-5 and ZO-1 immunostaining in cilostazol-treated RBEC, more data are needed concerning the presence of phosphorylated claudin-5 and ZO-1 in cilostazol-treated RBEC.

We extended the previous finding of Torii et al. (2007), who showed that cilostazol strengthens barrier integrity in peripheral human umbilical vein endothelial cells (HUVEC), by studying F-actin distribution in RBEC. We found that cilostazol rearranged cytoskeletal F-actin networks with redistribution at the cell border. A similar observation was made in the case of human brain endothelial cells treated with a high dose of cilostazol (Liu et al. 2012) and of RBEC and HUVEC treated with adrenomedullin2, an autocrine mediator of endothelial cell activation of cAMP/PKA 
and cAMP/EPAC1 signalings (Chen et al. 2006; Aslam et al. 2012). Spindler and Wacheke (2011) reported that cAMP/PKA and cAMP/EPAC1 signaling-mediated Rac1 activation by $\beta$-adrenergic stimulation influences rearrangement and linearized-bundle formation on cytoskeletal F-actin networks, and stabilization of adherence junctions in the cell border, to increase barrier tightness with a high TEER in human dermal microvascular endothelial cells (HDMEC). Noda et al. (2010) also found that Rap1, a small Ras-related GTPase selectively activated by cAMP/EPAC1 signaling, acted on the cell border of HUVEC to stabilize VE-cadherin in adherens junctions and rearrange F-actin bundle formation. Hence, pathways of cAMP/PKA and cAMP/EPAC1 signalings may independently function to regulate barrier integrity in endothelial cells. The present finding that cilostazol-induced barrier tightness was dependent on PKA supports the idea of an independent role of cAMP/PKA and cAMP/EPAC1 signaling on endothelial barrier integrity.

Effect of Cilostazol on Barrier Function of RBEC damaged by in vitro OGD and Reoxygenation

Cilostazol was also tested on an experimental model of cerebral ischemia-related BBB damage with $\mathrm{TJ}$ dysfunction using $\mathrm{BBB} \mathrm{Kit}^{\mathrm{TM}}$, a co-culture model constructed from primary RBEC, primary rat pericytes and primary rat astrocytes (Nakagawa et al. 2007, 2009). This model allows cross-talk between the cells and pathological events at the level of the BBB can be analyzed in vitro. The chosen exposure time of $6 \mathrm{~h}$ for OGD and $3 \mathrm{~h}$ for reoxygenation can be considered as conditions representative of transient cerebral ischemia and reperfusion (Tixier et al. 2008). We have succeeded in 
constructing an experimental model of cerebral ischemia-related BBB damage with TJ dysfunction with three types of primarily cultured BBB-related cells: RBEC, rat pericytes and rat astrocytes (Nakagawa et al. 2007, 2009). In this model we chose an exposure time of $6 \mathrm{~h}$ in OGD and $3 \mathrm{~h}$ in reoxygenation as conditions representative of transient cerebral ischemia and reperfusion (Tixier et al. 2008). Ceruti et al. (2011) and Al Ahmad et al. (2012) showed a distinctive role of the same BBB-related cells in an OGD-induced BBB damage. The triple co-culture BBB model exposed to OGD/reoxygenation was shown to be useful to evaluate the pharmacological efficacy of drugs in protecting the BBB from ischemic insult.

Of particular interest was the present observation that cilostazol treated BBB $\mathrm{Kit}^{\mathrm{TM}}$ damaged by in vitro ischemic insult to recover barrier tightness, a finding supporting the new pharmacological spectrum of cilostazol for protecting the BBB from cerebral ischemia. This protective effect of cilostazol is in accordance with the previous findings that cilostazol improved cerebral infarction by reducing cytotoxic edema in rats (Lee et al. 2003; Ito et al. 2010; Wajima et al. 2011). Cilostazol also reversed the reduction of claudin-5 expression and normalized the increase of MMP-9 activity to prevent tissue plasminogen activator (tPA)-associated hemorrhagic transformation induced by focal cerebral ischemia in mice treated with tPA (Ishiguro et al. 2010). Cilostazol protected HUVEC against 6-h OGD/0.5-h reoxygenation-induced damage by upregulation of VE-cadherin in a cAMP/PKA signaling-dependent manner (Ishiguro et al. 2011). Little is known about the effect of cilostazol on BBB-related cells, especially in pathological conditions. The pharmacological effect of cilostazol on cross-talk between BBB-related cells in the NVU protecting the BBB against cerebral ischemia will be elucidated when more is known of the cellular changes in the respective cells of 
the $\mathrm{BBB} \mathrm{Kit}^{\mathrm{TM}}$ in conditions modeling ischemia.

Effect of Cilostazol on Efflux Pump Activity

We used the immortalized human brain endothelial cell line hCMEC/D3 (Weksler et al. 2005) to evaluate the effect of cilostazol on P-glycoprotein transporter function (Tai et al. 2009; Carl et al. 2010; Chan et al. 2011). Poller et al. (2010) noted a diverse effect of TNF- $\alpha$ on P-glycoprotein activity and protein expression between hCMEC/D3 and rodent cells, a phenomenon based on species-difference. Cilostazol increased P-glycoprotein transporter activity in hCMEC/D3 cells at concentrations pertinent to the clinical serum levels of 1.35 2.71 $\mu \mathrm{M}$ (Kajinami et al. 2000). This effect was blocked by PKA inhibitor H-89. We noticed that the effect on P-glycoprotein in hCMEC/D3 cells was dependent on the time-scale of cilostazol treatment. There was an increase of P-glycoprotein function in hCMEC/D3 cells treated with cilostazol for $24 \mathrm{~h}$ and $96 \mathrm{~h}$, but no effect was observed in cells treated for $6 \mathrm{~h}$ and $12 \mathrm{~h}$. These findings are in agreement with previous observations from our laboratory, that cAMP increases P-glycoprotein activity in GP8 rat brain endothelial cells (Deli et al. 2001) as well as in primary rat brain endothelial cells (Perrière et al. 2007).

Hartz et al. (2004, 2006) found that P-glycoprotein in the rat brain capillary is possibly phosphorylated by $\mathrm{PKC}$ to decrease its transporter activity by short-term regulation. Possible participation of cilostazol in the phosphorylation of P-glycoprotein may not be excluded, however the transporter activity modulated by PKC activation was in the order of minutes. Thus, taken together with the present finding that cilostazol is not a P-glycoprotein substrate, it may be true that the cilostazol-induced increase in 
P-glycoprotein function is due to long-term regulation such as transcriptional activation of the P-glycoprotein encoding gene MDR1 or acceleration of protein trafficking to the apical plasma membrane.

To respond to xenobiotics, stress and central nervous diseases, transcriptional factors such as pregnane-X receptor, nuclear factor (NF)- $\mathrm{B}$, activator protein-1 and constitutive androstane receptor (CAR) are activated to increase P-glycoprotein expression in the BBB. Epileptic seizures increase efflux pump activity at the BBB by activation of NMDA receptor and NF-אB (Miller 2010; Potschka 2010). There has been a report that cAMP response elements in the MDR1 gene and MDR1 expression can be modulated by the cAMP/PKA pathway and selective PKA inhibitors can downregulate P-glycoprotein expression in chemoresistant tumor cells (Rohlff and Glazer, 1995). Ziemann et al. (2006) provided evidence that prostaglandin E2 (PGE2) EP receptor-mediated cAMP/PKA activation stimulates CREB or CREB-related proteins during $m d r 1 b$ gene expression in primary rat hepatocytes. Recently, in hCMEC/D3 cells, agonists of PGE2 receptors were found to induce MDR1 mRNA levels (Yousif et al. 2012). Furthermore, adenosine receptor-mediated cAMP production became evident in hCMEC/D3 cells (Mills et al. 2011). Thus, we speculate that cilostazol increases the level of functional P-glycoprotein protein in hCMEC/D3 cells through cAMP elevating signal-related $M D R 1$ gene expression.

Alternatively, cilostazol may accelerate translocation and internalization of P-glycoprotein from the cellular cytoplasm to the apical plasma membrane in hCMEC/D3 cells. In human HepG2 cells there is evidence that cAMP/PKA signaling stimulates the trafficking of P-glycoprotein on a time scale of 1 day (Wojtal et al. 2006). Modification of PDE3B inhibition for P-glycoprotein turnover in brain endothelial cells 
remains to be investigated.

Lim et al. (2008) found that in hCMEC/D3 cells GSK-3 $\beta$ inhibitors and a Wnt agonist up-regulated $\beta$-catenin signaling to increase cellular P-glycoprotein. cAMP/PKA signaling depressed the activity of AMP-activated protein kinase (AMPK) (Djouder et al. 2010), a kinase phosphorylating GSK-3 $\beta$, to reduce cellular levels of $\beta$-catenin (Kim et al. 2011; Hien et al. 2010), and activated Rac1 to increase nuclear accumulation of $\beta$-catenin (Wu et al. 2008). We suppose that cilostazol intervened in Wnt/ $\beta$-catenin signaling to induce the transcriptional activation of the P-glycoprotein encoding gene MDR1, although the protein level was not quantified in hCMEC/D3 cells treated with cilostazol in this study. Thus, taken in conjunction with our own data, the possibility that cilostazol exerts a pharmacological effect on the both TJs and P-glycoprotein in the BBB would have to be considered.

In summary, we report what seems to be the first evidence that cilostazol, a selective inhibitor of PDE3, acts directly on brain endothelial cells, improves the function of TJs and P-glycoprotein of the BBB, and protects from OGD/reoxygenation-induced BBB damage, presumably in an intracellular cAMP/PKA signaling-dependent manner. Taken together with the recently reported clinical significance of cilostazol for the prevention of secondary cerebral stroke after ischemic stroke (Shinohara et al. 2010), therapeutic approaches with cilostazol to treat dementia diseases with ischemia-related neuronal death would appear to have merit. Our present results on cilostazol will pave the way for the development of BBB-protective drugs across the pharmacological spectrum of PDE3B.

Acknowledgments Cilostazol was kindly provided by Otsuka Pharmaceutical Co., Ltd., Tokushima, Japan. This work was supported in part by a Grant-in-Aid for 
Scientific Research (C) (22590243) and a Grant-in-Aid for Young Scientists (B) (24790258) from the Japan Society for the Promotion of Science (JSPS), Japan.

\section{References}

Abbott NJ, Patabendige AA, Dolman DE, Yusof SR, Begley DJ (2010) Structure and function of the blood-brain barrier. Neurobiol Dis 37:13-25

Al Ahmad A, Gassmann M, Ogunshola OO (2012) Involvement of oxidative stress in hypoxia-induced blood-brain barrier breakdown. Microvasc Res 84:222-225

Aslam M, Pfeil U, Gunduz D, Rafiq A, Kummer W, Piper HM, Noll T (2012) Intermedin (adrenomedullin2) stabilizes the endothelial barrier and antagonizes thrombin-induced barrier failure in endothelial cell monolayers. Br J Pharmacol 165:208-222

Baltes S, Gastens AM, Fedrowitz M, Potschka H, Kaever V, Löscher W (2007) Differences in the transport of the antiepileptic drugs phenytoin, levetiracetam and carbamazepine by human and mouse P-glycoprotein. Neuropharmacology 52:333-346

Beckers CM, van Hinsbergh VW, van Nieuw Amerongen GP (2010) Driving Rho GTPase activity in endothelial cells regulates barrier integrity. Thromb Haemostasis 103:40-55

Carl SM, Lindley DJ, Couraud PO, Weksler BB, Romero I, Mowery SA, Knipp GT (2010) ABC and SLC transporter expression and pot substrate characterization across the human CMEC/D3 blood-brain barrier cell line. Mol Pharmcol 7:1057-1068

Carman AJ, Mills JH, Krenz A, Kim DG, Bynoe MS (2011) Adenosine receptor signaling modulates permeability of the blood-brain barrier. J Neurosci 31:13272-13280

Ceruti S, Colombo L, Magni G, Vigano F, Boccazzi M, Deli MA, Sperlagh B, Abbracchio MP, Kittel A (2011) Oxygen-glucose deprivation increases the enzymatic activity and the microvesicle-mediated release of ectonucleotidases in the cells composing the blood-brain barrier. Neurochem Int 59:259-271

Chan GN, Hoque MT, Cummins CL, Bendayan R (2011) Regulation of P-glycoprotein by orphan nuclear receptors in human brain microvessel endothelial cells. J Neurochem 118:163-175 
Chen L, Kis B, Hashimoto H, Busija DW, Takei Y, Yamashita H, Ueta Y (2006) Adrenomedullin 2 protects rat cerebral endothelial cells from oxidative damage in vitro. Brain Res 1086:42-49

Cheng D, Ren J, Gillespie DG, Mi Z, Jackson EK (2010) Regulation of 3',5'-cAMP in preglomerular smooth muscle and endothelial cells from genetically hypertensive rats. Hypertension 56:1096-1101

Cheng J, Thompson MA, Walker HJ, Gray CE, Diaz Encarnacion MM, Warner GM, Grande JP (2004) Differential regulation of mesangial cell mitogenesis by cAMP phosphodiesterase isozymes 3 and 4. Am J Physiol Renal Physiol 287:F940-F953

Choi JM, Shin HK, Kim KY, Lee JH, Hong KW (2002) Neuroprotective effect of cilostazol against focal cerebral ischemia via antiapoptotic action in rats. J Pharmacol Exp Ther 300:787-793

Deli MA, Szabo C, Dung N, Joo F (1997) Immunohistochemical and electron microscopy detections on primary cultures of rat cerebral endothelial cells. In: Boer AG, Sutanto W (eds) Drug transport across the blood-brain barrier: In vivo and in vitro techniques. Harwood Academic Publishers, Amsterdam, pp 23-28

Deli MA, Ábrahám CS, Takahata H, Niwa M (2001) Tissue plasminogen activator inhibits P-glycoprotein activity in brain endothelial cells. Eur J Pharmacol 411:R3-R5

Deli MA, Abraham CS, Kataoka Y, Niwa M (2005) Permeability studies on in vitro blood-brain barrier models: physiology, pathology, and pharmacology. Cell Mol Neurobiol 25:59-127

Deli MA, Veszelka S, Csiszar B, Toth A, Kittel A, Csete M, Sipos A, Szalai A, Fulop L, Penke B, Abraham CS, Niwa M (2010) Protection of the blood-brain barrier by pentosan against amyloid- $\beta$-induced toxicity. J Alzheimers Dis 22:777-794

Di Benedetto G, Zoccarato A, Lissandron V, Terrin A, Li X, Houslay MD, Baillie GS, Zaccolo M (2008) Protein kinase A type I and type II define distinct intracellular signaling compartments. Circ Res 103:836-844

Djouder N, Tuerk RD, Suter M, Salvioni P, Thali RF, Scholz R, Vaahtomeri K, Auchli Y, Rechsteiner H, Brunisholz RA, Viollet B, Mäkelä TP, Wallimann T, Neumann D, Krek W (2010) PKA phosphorylates and inactivates AMPK $\alpha$ to promote efficient lipolysis. EMBO J 29:469-481 
Elias BC, Suzuki T, Seth A, Giorgianni F, Kale G, Shen L, Turner JR, Naren A, Desiderio DM, Rao R (2009) Phosphorylation of Tyr-398 and Tyr-402 in occludin prevents its interaction with ZO-1 and destabilizes its assembly at the tight junctions. J Biol Chem 284:1559-1569

Feinstein WP, Zhu B, Leavesley SJ, Sayner SL, Rich TC (2012) Assessment of cellular mechanisms contributing to cAMP compartmentalization in pulmonary microvascular endothelial cells. Am J Physiol Cell Physiol 302:C839-852

Fontaine M, Elmquist WF, Miller DW (1996) Use of rhodamine 123 to examine the functional activity of P-glycoprotein in primary cultured brain microvessel endothelial cell monolayers. Life Sci 59:1521-1531

Furuse M, Tsukita S (2006) Claudins in occluding junctions of humans and flies. Trends Cell Biol $16: 181-188$

Goldblum SE, Rai U, Tripathi A, Thakar M, De Leo L, Di Toro N, Not T, Ramachandran R, Puche AC, Hollenberg MD, Fasano A (2011) The active Zot domain (aa 288-293) increases ZO-1 and myosin 1C serine/threonine phosphorylation, alters interaction between ZO-1 and its binding partners, and induces tight junction disassembly through proteinase activated receptor 2 activation. FASEB J 25:144-158

Haorah J, Ramirez SH, Schall K, Smith D, Pandya R, Persidsky Y (2007) Oxidative stress activates protein tyrosine kinase and matrix metalloproteinases leading to blood-brain barrier dysfunction. J Neurochem 101:566-576

Hartz AM, Bauer B, Fricker G, Miller DS (2004) Rapid regulation of P-glycoprotein at the blood-brain barrier by endothelin-1. Mol Pharmacol 66:387-394

Hartz AM, Bauer B, Fricker G, Miller DS (2006) Rapid modulation of P-glycoprotein-mediated transport at the blood-brain barrier by tumor necrosis factor- $\alpha$ and lipopolysaccharide. Mol Pharmacol 69:462-470

Hermann DM, Elali A (2012) The abluminal endothelial membrane in neurovascular remodeling in health and disease. Sci Signal 5:re4 
Hidaka H, Kobayashi R (1992) Pharmacology of protein kinase inhibitors. Annu Rev Pharmacol Toxicol 32:377-397

Hien TT, Kim HG, Han EH, Kang KW, Jeong HG (2010) Molecular mechanism of suppression of MDR1 by puerarin from Pueraria lobata via NF- $\mathrm{B}$ pathway and cAMP-responsive element transcriptional activity-dependent up-regulation of AMP-activated protein kinase in breast cancer MCF-7/adr cells. Mol Nutr Food Res 54:918-928

Hoheisel D, Nitz T, Franke H, Wegener J, Hakvoort A, Tilling T, Galla HJ (1998) Hydrocortisone reinforces the blood-brain properties in a serum free cell culture system. Biochem Bioph Res Co 247:312-315

Hong KW, Lee JH, Kima KY, Park SY, Lee WS (2006) Cilostazol: therapeutic potential against focal cerebral ischemic damage. Curr Pharm Design 12:565-573

Ishiguro M, Mishiro K, Fujiwara Y, Chen H, Izuta H, Tsuruma K, Shimazawa M, Yoshimura S, Satoh M, Iwama T, Hara H (2010) Phosphodiesterase-III inhibitor prevents hemorrhagic transformation induced by focal cerebral ischemia in mice treated with tPA. PLoS One 2010;5:e15178

Ishiguro M, Suzuki Y, Mishiro K, Kakino M, Tsuruma K, Shimazawa M, Yoshimura S, Iwama T, Hara H (2011) Blockade of phosphodiesterase-III protects against oxygen-glucose deprivation in endothelial cells by upregulation of VE-cadherin. Curr Neurovasc Res 8:86-94

Ishizaki T, Chiba H, Kojima T, Fujibe M, Soma T, Miyajima H, Nagasawa K, Wada I, Sawada N (2003) Cyclic AMP induces phosphorylation of claudin-5 immunoprecipitates and expression of claudin-5 gene in blood-brain-barrier endothelial cells via protein kinase A-dependent and -independent pathways. Exp Cell Res 290:275-288

Ito H, Hashimoto A, Matsumoto Y, Yao H, Miyakoda G (2010) Cilostazol, a phosphodiesterase inhibitor, attenuates photothrombotic focal ischemic brain injury in hypertensive rats. J Cereb Blood Flow Metab 30:343-351

Kajinami K, Koizumi J, Ueda K, Miyamoto S, Takegoshi T, Mabuchi H (2000) Effects of NK-104, a new hydroxymethylglutaryl-coenzyme reductase inhibitor, on low-density lipoprotein cholesterol in heterozygous familial hypercholesterolemia. Hokuriku NK-104 Study Group. Am J Cardiol 85:178-183 
Kelley DJ, Davidson RJ, Elliott JL, Lahvis GP, Yin JC, Bhattacharyya A (2007) The cyclic AMP cascade is altered in the fragile $\mathrm{X}$ nervous system. PLoS One 2:e931

Kim M, Park AJ, Havekes R, Chay A, Guercio LA, Oliveira RF, Abel T, Blackwell KT (2011) Colocalization of protein kinase A with adenylyl cyclase enhances protein kinase A activity during induction of long-lasting long-term-potentiation. PLoS Comput Biol 7:e1002084

Kis B, Chen L, Ueta Y, Busija DW (2006) Autocrine peptide mediators of cerebral endothelial cells and their role in the regulation of blood-brain barrier. Peptides 27:211-222

Kis B, Deli MA, Kobayashi H, Abraham CS, Yanagita T, Kaiya H, Isse T, Nishi R, Gotoh S, Kangawa K, Wada A, Greenwood J, Niwa M, Yamashita H, Ueta Y (2001) Adrenomedullin regulates blood-brain barrier functions in vitro. Neuroreport 12:4139-4142

Koto T, Takubo K, Ishida S, Shinoda H, Inoue M, Tsubota K, Okada Y, Ikeda E (2007) Hypoxia disrupts the barrier function of neural blood vessels through changes in the expression of claudin-5 in endothelial cells. Am J Pathol 170:1389-1397

Lee DH, Lee HR, Shin HK, Park SY, Hong KW, Kim EK, Bae SS, Lee WS, Rhim BY, Kim CD (2011) Cilostazol enhances integrin-dependent homing of progenitor cells by activation of cAMP-dependent protein kinase in synergy with Epac1. J Neurosci Res 89:650-660

Lee JH, Lee YK, Ishikawa M, Koga K, Fukunaga M, Miyakoda G, Mori T, Hosokawa T, Hong KW (2003) Cilostazol reduces brain lesion induced by focal cerebral ischemia in rats-an MRI study. Brain Res 994:91-98

Lee JH, Shin HK, Park SY, Kim CD, Lee WS, Hong KW (2009) Cilostazol preserves CA1 hippocampus and enhances generation of immature neuroblasts in dentate gyrus after transient forebrain ischemia in rats. Exp Neurol 215:87-94

Lim JC, Kania KD, Wijesuriya H, Chawla S, Sethi JK, Pulaski L, Romero IA, Couraud PO, Weksler BB, Hladky SB, Barrand MA (2008) Activation of $\beta$-catenin signalling by GSK-3 inhibition increases p-glycoprotein expression in brain endothelial cells. J Neurochem 106:1855-1865

Liu S, Yu C, Yang F, Paganini-Hill A, Fisher MJ (2012) Phosphodiesterase inhibitor modulation of brain 
microvascular endothelial cell barrier properties. J Neurol Sci 320:45-51

Lorenowicz MJ, Fernandez-Borja M, Kooistra MR, Bos JL, Hordijk PL (2008) PKA and Epac1 regulate endothelial integrity and migration through parallel and independent pathways. Eur J Cell Biol 87:779-792

Lugnier C (2006) Cyclic nucleotide phosphodiesterase (PDE) superfamily: a new target for the development of specific therapeutic agents. Pharmacol Ther 109:366-398

Mackic JB, Stins M, McComb JG, Calero M, Ghiso J, Kim KS, Yan SD, Stern D, Schmidt AM, Frangione B, Zlokovic BV (1998) Human blood-brain barrier receptors for Alzheimer's amyloid- $\beta$ 1- 40. Asymmetrical binding, endocytosis, and transcytosis at the apical side of brain microvascular endothelial cell monolayer. J Clin Invest 102:734-743

Maurice DH (2011) Subcellular signaling in the endothelium: cyclic nucleotides take their place. Curr Opin Pharmacol 11:656-664

Miki T, Taira M, Hockman S, Shimada F, Lieman J, Napolitano M, Ward D, Taira M, Makino H, Manganiello VC (1996) Characterization of the cDNA and gene encoding human PDE3B, the cGIP1 isoform of the human cyclic GMP-inhibited cyclic nucleotide phosphodiesterase family. Genomics 36:476-485

Miller DS (2010) Regulation of P-glycoprotein and other ABC drug transporters at the blood-brain barrier. Trends Pharmacol Sci 31:246-254

Mills JH, Alabanza L, Weksler BB, Couraud P-O, Romero IA, Bynoe MS (2011) Human brain endothelial cells are responsive to adenosine receptor activation. Purinerg Signal 7:265-273

Morofuji Y, Nakagawa S, So G, Hiu T, Horai S, Hayashi K, Tanaka K, Suyama K, Deli MA, Nagata I, Niwa M (2010) Pitavastatin strengthens the barrier integrity in primary cultures of rat brain endothelial cells. Cell Mol Neurobiol 30:727-735

Nakagawa S, Deli MA, Kawaguchi H, Shimizudani T, Shimono T, Kittel A, Tanaka K, Niwa M (2009) A new blood-brain barrier model using primary rat brain endothelial cells, pericytes and astrocytes. Neurochem Int 54:253-263 
Nakagawa S, Deli MA, Nakao S, Honda M, Hayashi K, Nakaoke R, Kataoka Y, Niwa M (2007) Pericytes from brain microvessels strengthen the barrier integrity in primary cultures of rat brain endothelial cells. Cell Mol Neurobiol 27:687-694

Netherton SJ, Maurice DH (2005) Vascular endothelial cell cyclic nucleotide phosphodiesterases and regulated cell migration: implications in angiogenesis. Mol Pharmacol 67:263-272

Neuwelt E, Abbott NJ, Abrey L, Banks WA, Blakley B, Davis T, Engelhardt B, Grammas P, Nedergaard M, Nutt J, Pardridge W, Rosenberg GA, Smith Q, Drewes LR (2008) Strategies to advance translational research into brain barriers. Lancet Neurol 7:84-96

Nishitsuji K, Hosono T, Nakamura T, Bu G, Michikawa M (2011) Apolipoprotein E regulates the integrity of tight junctions in an isoform-dependent manner in an in vitro blood-brain barrier model. J Biol Chem 286:17536-17542

Nitta T, Hata M, Gotoh S, Seo Y, Sasaki H, Hashimoto N, Furuse M, Tsukita S (2003) Size-selective loosening of the blood-brain barrier in claudin-5-deficient mice. J Cell Biol 161:653-660

Nitz T, Eisenblätter T, Psathaki K, Galla H-J (2003) Serum-drived factor weaken the barrier properties of culutured procine brain capillary endothelial cells in vitro. Brain Res 981:30-40

Noda K, Zhang J, Fukuhara S, Kunimoto S, Yoshimura M, Mochizuki N (2010) Vascular endothelial-cadherin stabilizes at cell-cell junctions by anchoring to circumferential actin bundles through $\alpha$ - and $\beta$-catenins in cyclic AMP-Epac-Rap1 signal-activated endothelial cells. Mol Biol Cell 21:584-596

Omori K, Kotera J (2007) Overview of PDEs and their regulation. Circ Res 100:309-327

Perrière N, Demeuse P, Garcia E, Regina A, Debray M, Andreux JP, Couvreur P, Scherrmann JM, Temsamani J, Couraud PO, Deli MA, Roux F (2005) Puromycin-based purification of rat brain capillary endothelial cell cultures. Effect on the expression of blood-brain barrier-specific properties. J Neurochem 93:279-289

Perrière N, Yousif S, Cazaubon S, Chaverot N, Bourasset F, Cisternino S, Declèves X, Hori S, Terasaki T, Deli M, Scherrmann JM, Temsamani J, Roux F, Couraud PO (2007) A functional in vitro model of rat blood-brain barrier for molecular analysis of efflux transporters. Brain Res 1150:1-13 
Poller B, Drewe J, Krahenbuhl S, Huwyler J, Gutmann H (2010) Regulation of BCRP (ABCG2) and P-glycoprotein (ABCB1) by cytokines in a model of the human blood-brain barrier. Cell Mol Neurobiol 30:63-70

Poller B, Gutmann H, Krahenbuhl S, Weksler B, Romero I, Couraud PO, Tuffin G, Drewe J, Huwyler J (2008) The human brain endothelial cell line hCMEC/D3 as a human blood-brain barrier model for drug transport studies. J Neurochem 107:1358-1368

Potschka H (2010) Modulating P-glycoprotein regulation: future perspectives for pharmacoresistant epilepsies? Epilepsia 51:1333-1347

Rampersad SN, Ovens JD, Huston E, Umana MB, Wilson LS, Netherton SJ, Lynch MJ, Baillie GS, Houslay MD, Maurice DH (2010) Cyclic AMP phosphodiesterase 4D (PDE4D) Tethers EPAC1 in a vascular endothelial cadherin (VE-Cad)-based signaling complex and controls cAMP-mediated vascular permeability. J Biol Chem 285:33614-33622

Reinhardt RR, Chin E, Zhou J, Taira M, Murata T, Manganiello VC, Bondy CA (1995) Distinctive anatomical patterns of gene expression for cGMP-inhibited cyclic nucleotide phosphodiesterases. J Clin Invest 95:1528-1538

Rohlff C, Glazer RI (1995) Regulation of multidrug resistance through the cAMP and EGF signalling pathways. Cell Signal 7:431-443

Rubin LL, Staddon JM, The cell bilogy of the blood-brain barrier (1999) Annu Rev Neurosci 22:11-28

Sayner SL (2011) Emerging themes of cAMP regulation of the pulmonary endothelial barrier. Am J Physiol Lung Cell Mol Physiol 300:L667-L678

Schankin CJ, Kruse LS, Reinisch VM, Jungmann S, Kristensen JC, Grau S, Ferrari U, Sinicina I, Goldbrunner R, Straube A, Kruuse C (2010) Nitric oxide-induced changes in endothelial expression of phosphodiesterases 2, 3, and 5. Headache 50:431-441

Shinohara Y, Katayama Y, Uchiyama S, Yamaguchi T, Handa S, Matsuoka K, Ohashi Y, Tanahashi N, Yamamoto H, Genka C, Kitagawa Y, Kusuoka H, Nishimaru K, Tsushima M, Koretsune Y, Sawada T, Hamada C (2010) Cilostazol for prevention of secondary stroke (CSPS 2): an aspirin-controlled, 
double-blind, randomised non-inferiority trial. Lancet Neurol 9:959-968

Soma T, Chiba H, Kato-Mori Y, Wada T, Yamashita T, Kojima T, Sawada N (2004) Thr (207) of claudin-5 is involved in size-selective loosening of the endothelial barrier by cyclic AMP. Exp Cell Res 300:202-212

Spindler V, Schlegel N, Waschke J (2010) Role of GTPases in control of microvascular permeability. Cardiovasc Res 87:243-253

Spindler V, Waschke J (2011) Beta-adrenergic stimulation contributes to maintenance of endothelial barrier functions under baseline conditions. Microcirculation 18:118-127

Sudo T, Tachibana K, Toga K, Tochizawa S, Inoue Y, Kimura Y, Hidaka H (2000) Potent effects of novel anti-platelet aggregatory cilostamide analogues on recombinant cyclic nucleotide phosphodiesterase isozyme activity. Biochemical pharmacology 59:347-356

Suzuki T, Elias BC, Seth A, Shen L, Turner JR, Giorgianni F, Desiderio D, Guntaka R, Rao R (2009) PKC eta regulates occludin phosphorylation and epithelial tight junction integrity. Proc Natl Acad Sci U S A 106:61-66

Taddei A, Giampietro C, Conti A, Orsenigo F, Breviario F, Pirazzoli V, Potente M, Daly C, Dimmeler S, Dejana E (2008) Endothelial adherens junctions control tight junctions by VE-cadherin-mediated upregulation of claudin-5. Nat Cell Biol 10:923-934

Tai LM, Reddy PS, Lopez-Ramirez MA, Davies HA, Male DK, Loughlin AJ, Romero IA (2009) Polarized P-glycoprotein expression by the immortalised human brain endothelial cell line, hCMEC/D3, restricts apical-to-basolateral permeability to rhodamine 123. Brain Res 1292:14-24

Thompson PD, Zimet R, Forbes WP, Zhang P (2002) Meta-analysis of results from eight randomized, placebo-controlled trials on the effect of cilostazol on patients with intermittent claudication. Am J Cardiol 90:1314-1319

Tixier E, Leconte C, Touzani O, Roussel S, Petit E, Bernaudin M (2008) Adrenomedullin protects neurons against oxygen glucose deprivation stress in an autocrine and paracrine manner. $\mathrm{J}$ Neurochem 106:1388-1403 
Torii H, Kubota H, Ishihara H, Suzuki M (2007) Cilostazol inhibits the redistribution of the actin cytoskeleton and junctional proteins on the blood-brain barrier under hypoxia/reoxygenation. Pharmacol Res 55:104-110

Tsukita S, Yamazaki Y, Katsuno T, Tamura A, Tsukita S (2008) Tight junction-based epithelial microenvironment and cell proliferation. Oncogene 27:6930-6938

Wajima D, Nakamura M, Horiuchi K, Takeshima Y, Nishimura F, Nakase H (2011) Cilostazol minimizes venous ischemic injury in diabetic and normal rats. J Cereb Blood Flow Metab 31:2030-2040

Watanabe T, Zhang N, Liu M, Tanaka R, Mizuno Y, Urabe T (2006) Cilostazol protects against brain white matter damage and cognitive impairment in a rat model of chronic cerebral hypoperfusion. Stroke 37:1539-1545

Weksler BB, Subileau EA, Perrière N, Charneau P, Holloway K, Leveque M, Tricoire-Leignel H, Nicotra A, Bourdoulous S, Turowski P, Male DK, Roux F, Greenwood J, Romero IA, Couraud PO (2005) Blood-brain barrier-specific properties of a human adult brain endothelial cell line. FASEB J 19:1872-1874

Wilson LS, Baillie GS, Pritchard LM, Umana B, Terrin A, Zaccolo M, Houslay MD, Maurice DH (2011) A phosphodiesterase 3B-based signaling complex integrates exchange protein activated by cAMP 1 and phosphatidylinositol 3-kinase signals in human arterial endothelial cells. J Biol Chem 286:16285-16296

Wojtal KA, de Vries E, Hoekstra D, van Ijzendoorn SCD (2006) Efficient trafficking of MDR1/P-glycoprotein to apical canalicular plasma membranes in HepG2 cells requires PKA-RII $\alpha$ anchoring and glucosylceramide. Mol Biol Cell 17:3638-3650

Wu X, Tu X, Joeng KS, Hilton MJ, Williams DA, Long F (2008) Rac1 activation controls nuclear localization of $\beta$-catenin during canonical Wnt signaling. Cell 133:340-353

Yamamoto M, Ramirez SH, Sato S, Kiyota T, Cerny RL, Kaibuchi K, Persidsky Y, Ikezu T (2008) Phosphorylation of claudin-5 and occludin by rho kinase in brain endothelial cells. Am J Pathol $172: 521-533$

Youdim KA, Avdeef A, Abbott NJ (2003) In vitro trans-monolayer permeability calculations: often 
forgotten assumptions. Drug Discov Today 8:997-1003

Yousif S, Chaves C, Potin S, Margaill I, Scherrmann JM, Decleves X (2012) Induction of P-glycoprotein and Bcrp at the rat blood-brain barrier following a subchronic morphine treatment is mediated through NMDA/COX-2 activation. J Neurochem 123:491-503

Zaccolo M (2011) Spatial control of cAMP signalling in health and disease. Curr Opin Pharmacol 11:649-655

Ziemann C, Riecke A, Rudell G, Oetjen E, Steinfelder HJ, Lass C, Kahl GF, Hirsch-Ernst KI (2006) The role of prostaglandin E receptor-dependent signaling via cAMP in $M d r 1 b$ gene activation in primary rat hepatocyte cultures. J Pharmacol Exp Ther 317:378-386

Zlokovic BV (2011) Neurovascular pathways to neurodegeneration in Alzheimer's disease and other disorders. Nat Rev Neurosci 12:723-738 
Figure legends

Fig. 1 Schematic drawing of the experiments with primary cultures of rat brain capillary endothelial cells (RBEC) and the immortalized human brain endothelial cell line hCMEC/D3. (a) RBEC were isolated 4 days before the establishment of the in vitro BBB model. To purify cultures, cells were kept in the presence of puromycin ( $4 \mu \mathrm{g} / \mathrm{mL})$ for 2 days (RBEC I medium + puromycin). On Day 4, RBEC were plated on the top of polyester membranes of 12-well Transwell ${ }^{\circledR}$ inserts. From Day 5, RBEC were grown in culture medium containing $500 \mathrm{nM}$ hydrocortisone (RBEC II medium + hydrocortisone). Experiments were performed on Day 8 and 9. (b) hCMEC/D3 cells were plated in 24-well culture plates and cultured in EBM-2 medium with EGM-2 MV SingleQuots. On Day 5, experiments on P-glycoprotein were performed.

Fig. 2 Schematic drawing of the experiment with $\mathrm{BBB} \mathrm{Kit}^{\mathrm{TM}}$ subjected to oxygen glucose deprivation (OGD) and reoxygenation. In normoxia and 6-h OGD/3-h reoxygenation experiments, serum-free DMEM containing $4.5 \mathrm{~g} / \mathrm{L}$ glucose (glucose $^{+}$ DMEM) and serum- and glucose-free DMEM (glucose- DMEM) was added to BBB $\mathrm{Kit}^{\mathrm{TM}}$ (RBE-12), respectively. Six-hour hypoxia was generated using AnaeroPack ${ }^{\circledR}$. Reoxygenation was initiated by adding RBEC II medium with or without $1 \mu \mathrm{M}$ cilostazol and after 3 h TEER was measured to evaluate BBB barrier integrity.

Fig. 3 Expression of phosphodiesterase 3 (PDE3) mRNA (a) and effects of cilostazol on the intracellular content of cAMP (b) in rat brain capillary endothelial cells (RBEC). (a) Quantitative RT-PCR analysis detected significant expression of PDE3B mRNA in 
RBEC, whereas no expression of PDE3A mRNA was found. (b) Intracellular content of cAMP in RBEC increased when cells were treated with $1 \mu \mathrm{M}$ and $10 \mu \mathrm{M}$ cilostazol for $30 \mathrm{~min}$. All data (pmol/mg protein) are presented as mean \pm SEM (control, $\mathrm{n}=11 ; 1 \mu \mathrm{M}$, $\mathrm{n}=10 ; 10 \mu \mathrm{M}, \mathrm{n}=9) .{ }^{*} \mathrm{P}<0.05$ vs. control, ${ }^{* *} P<0.01$ vs. control

Fig. 4 Effects of cilostazol on interendothelial tight junction (TJ) functions in rat brain capillary endothelial cells (RBEC). TJ function was assessed by transendothelial electrical resistance (TEER) (a) and transendothelial permeability (Pe) of the paracellular transport marker sodium fluoresceine (Na-F) (b) across RBEC monolayers. a Cilosatzol dose-dependently and time-dependently increased TEER in RBEC. The cells were treated with increasing concentrations of cilostazol for up to $96 \mathrm{~h}$. A significantly higher level of TEER was detected in RBEC treated with $1 \mu \mathrm{M}$ (filled squares) for $24 \mathrm{~h}, 48 \mathrm{~h}, 72 \mathrm{~h}$ and $96 \mathrm{~h}$ and with $10 \mu \mathrm{M}$ cilostazol (open triangles) for 48 h, $72 \mathrm{~h}$ and $96 \mathrm{~h}\left({ }^{* *} P<0.01\right.$ vs. control). TEER values were expressed as a percentage of the control value $\left(100 \%\right.$ at $\left.96 \mathrm{~h}=196 \pm 26 \Omega \times \mathrm{cm}^{2}\right)$. All data are presented as mean \pm SEM $(n=13)$. b Cilosatzol dose-dependently reduced Na-F permeability (Pe) in RBEC. The cells were treated with increasing concentrations of cilosatzol for $96 \mathrm{~h}$. Significantly lower Na-F permeability (Pe) was detected in RBEC treated with $1 \mu \mathrm{M}$ and $10 \mu \mathrm{M}$ cilostazol $\left({ }^{* *} P<0.01\right.$ vs. control). The Pe values are expressed as a percentage of the control value $\left(100 \%=4.70 \pm 0.44 \times 10^{-6} \mathrm{~cm} / \mathrm{s}\right)$. All data are presented as mean $\pm \operatorname{SEM}(\mathrm{n}=12)$.

Fig. 5 Effect of protein kinase A (PKA) inhibitor H-89 on cilostazol-induced enhancement of interendothelial tight junction (TJ) functions in rat brain capillary 
endothelial cells (RBEC). TJ function was assessed by transendothelial electrical resistance (TEER) (a) and paracellular permeability (Pe) of sodium fluorescein (Na-F) (b) across RBEC monolayers. a TEER was significantly elevated in RBEC treated with $1 \mu \mathrm{M}$ cilostazol for $96 \mathrm{~h}$ (dark-gray column, ${ }^{* *} P<0.01$ vs. control). H-89 completely blocked cilostazol-induced increase in TEER when given to the cells at a concentration of $5 \mu \mathrm{M}$ simultaneously with cilostazol (black column, ${ }^{\#} P<0.01$ vs. H-89 ()) cilostazol (+) group). No change was observed in RBEC treated alone with H-89 for 96 h (light gray column). The TEER values are expressed as a percent of the control value (open column, $100 \%=215 \pm 13 \Omega \times \mathrm{cm}^{2}$ ). All data are presented as mean \pm SEM ( $\mathrm{n}=$ 7). b Na-F permeability was significantly reduced in RBEC treated with $1 \mu \mathrm{M}$ cilostazol for $96 \mathrm{~h}$ (dark-gray column, ${ }^{* *} P<0.01$ vs. control). H-89 completely blocked cilostazol-induced reduction in Na-F permeability when given to the cells at a concentration of $5 \mu \mathrm{M}$ simultaneously with cilostazol (black column, ${ }^{\# \#} P<0.01$ vs. H-89 (-) cilostazol (+) group). No change was observed in RBEC treated alone with H-89 for 96 h (light gray column). The Pe values are expressed as a percentage of the control value (open column, $100 \%=8.13 \pm 1.0610^{-6} \mathrm{~cm} / \mathrm{s}$ ). All data are presented as mean $\pm \operatorname{SEM}(\mathrm{n}=7)$.

Fig. 6 Immunofluorescent staining for tight junction (TJ) proteins claudin-5, occludin and ZO-1 and cytochemical staining of F-actin in rat brain capillary endothelial cells (RBEC). The boxed areas marked by dotted lines in the images of occludin (c, d) and F-actin (g, h) are enlarged in the bottom right corner. As indicated in the image of (c), a continuous, smooth, pericellular and belt-shaped pattern of occludin immunostaining was noted in RBEC treated with $1 \mu \mathrm{M}$ cilostazol for $96 \mathrm{~h}$ (c), as compared with the 
"zipper-like” and "prickly-leaf” pattern of irregularities in the control cells (d). Cilostazol also produced a smooth and sharp bundle of cytoskeletal F-actin along the RBEC border (g), although the control RBEC had numerous cytoplasmic-actin stress fibers (h). There was no significant difference between the images of claudin-5 (a, b) and ZO-1 (e, f) in RBEC treated with cilostazol and in the control cells. Bar $=20 \mu \mathrm{m}$.

Fig. 7 Effects of cilostazol on interendothelial tight junction (TJ) functions of rat brain capillary endothelial cells (RBEC) in the BBB Kit ${ }^{\mathrm{TM}}$ subjected to 6-h hypoxia and glucose deprivation (6-h OGD)/3-h reoxygenation, an in vitro model of transient cerebral ischemia and reperfusion. TJ function was assessed by transendothelial electrical resistance (TEER). TEER was significantly decreased in RBEC of the BBB $\mathrm{Kit}^{\mathrm{TM}}$ with 6-h OGD/3-h reoxygenation (dark gray column, ${ }^{* *} \mathrm{P}<0.01$ vs. normoxia control). When given to RBEC during the period of 3-h reoxygenation after 6-h OGD/3-h reoxygenation, cilostazol $(1 \mu \mathrm{M})$ inhibited the 6-h OGD/3-h reoxygenation-induced decrease in TEER (black column, ${ }^{\#} P<0.01$ vs. 6-h OGD/ 3-h reoxygenation control, ${ }^{* *} P<0.01$ vs. normoxia control). A significant increase in TEER was observed in RBEC treated with $1 \mu \mathrm{M}$ cilostazol for $3 \mathrm{~h}$ in normoxia experiments (** $P<0.01$ vs. normoxia control). TEER values are expressed as a percent of the control value (open column, $100 \%=84 \pm 14 \Omega \times \mathrm{cm}^{2}$, $\mathrm{n}=8$ ). All data are presented as mean $\pm \operatorname{SEM}(n=8)$.

Fig. 8 Effects of cilostazol and cyclosporine (CsA) on P-glycoprotein transporter function in the immortalized human brain endothelial cell line hCMEC/D3. P-glycoprotein function was assessed by the method of 1-h accumulation of rhodamine 
123 (R123). Cilostazol did not affect 1-h accumulation of R123 in hCMEC/D3 cells when given to the cells at a concentration of $10 \mu \mathrm{M}$ simultaneously with R123. An approximately 1.9-fold higher amount of R123 accumulated in hCMEC/D3 cells treated with $10 \mu \mathrm{M}$ CsA, an inhibitory substance of P-glycoprotein, for $1 \mathrm{~h}$ as compared with control cells (** $P<0.01$ vs. control). The R123 accumulation values are expressed as a percent of the control value $(100 \%=0.41 \pm 0.02 \mathrm{nmol} / \mathrm{mg}$ protein, $\mathrm{n}=10)$.

Fig. 9 Effects of cilostazol on P-glycoprtein transporter function in the immortalized human brain endothelial cell line hCMEC/D3. P-glycoprotein transporter function was assessed by the method of 1-h accumulation of rhodamine 123 (R123). a Cilostazol time-dependently reduced the 1-h accumulation of R123 in hCMEC/D3 cells. The cells were treated with $1.0 \mu \mathrm{M}$ cilostazol for 6 h, 12 h, 24 h and 96 h. A significant reduction was detected in hCMEC/D3 cells with 24-h and 96-h treatments of cilostazol, respectively ( $* P<0.05$ vs. control). R123 accumulation values are expressed as a percentage of the control value $(100 \%$ at $96 \mathrm{~h}=0.96 \pm 0.03 \mathrm{nmol} / \mathrm{mg}$ protein, $\mathrm{n}=10$ ) All data are presented as mean \pm SEM $(n=10)$. $\mathbf{b}$ Cilostazol dose-dependently reduced 1-h accumulation of R123 in hCMEC/D3 cells. The cells were treated with increasing concentrations of cilostazol for $24 \mathrm{~h}$. A significant reduction was detected in hCMEC/D3 cells with $1 \mu \mathrm{M}\left({ }^{*} P<0.05\right.$ vs. control) and $10 \mu \mathrm{M}\left({ }^{* *} P<0.01\right.$ vs. control) cilostazol, respectively. The R123 accumulation values are expressed as a percentage of the control value $(100 \%=0.40 \pm 0.07 \mathrm{nmol} / \mathrm{mg}$ protein, $\mathrm{n}=20)$. All data are presented as mean $\pm \operatorname{SEM}(\mathrm{n}=10)$.

Fig. 10 Effects of protein kinase A (PKA) inhibitor H-89 on cilostazol-induced 
enhancement of P-glycoprotein transporter function in the immortalized human brain endothelial cell line hCMEC/D3. P-glycoprotein transporter function was assessed by the method of 1-h accumulation of R123. One-h accumulation of R123 was significantly reduced in hCMEC/D3 cells treated with $1.0 \mu \mathrm{M}$ cilostazol for $24 \mathrm{~h}$ (dark-gray column, ${ }^{*} P<0.05$ vs. control). H-89 completely blocked cilostazol-induced reduction in 1-h accumulation of R123 when given to hCMEC/D3 cells at a concentration of $5.0 \mu \mathrm{M}$ simultaneously with $1.0 \mu \mathrm{M}$ cilostazol (black column, ${ }^{\#} P<$ 0.05 vs. H-89 (-) cilostazol (+) group). No change was observed in hCMEC/D3 cells treated alone with H-89 for 24 h (light gray column). The R123 accumulation values are expressed as a percent of the control value (open column, $100 \%=1.21 \pm 0.11 \mathrm{nmol} / \mathrm{mg}$ protein). All data are presented as mean \pm SEM $(n=12)$. 
Fig. 1

\section{A RBEC}

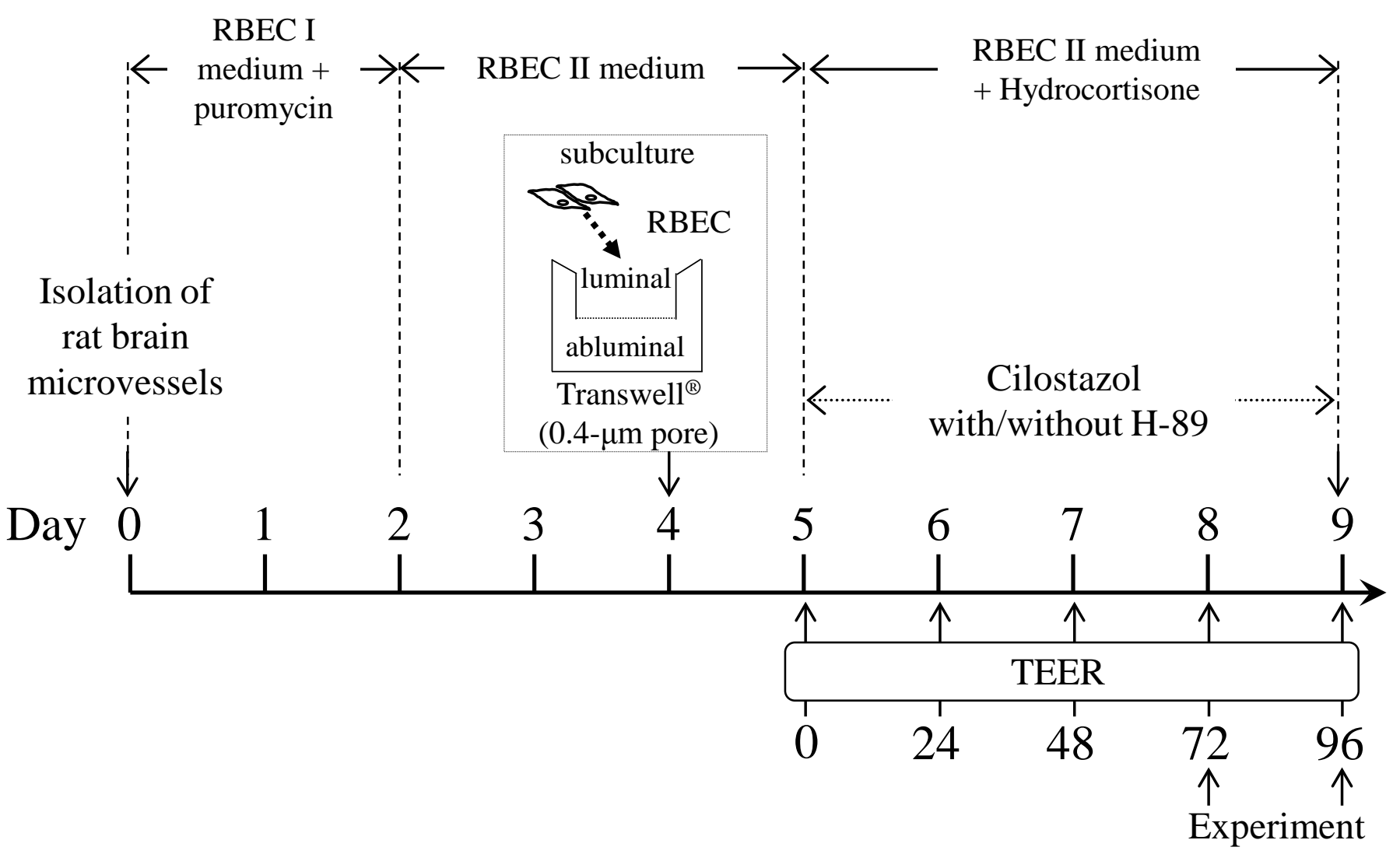

\section{B hCMEC/D3}

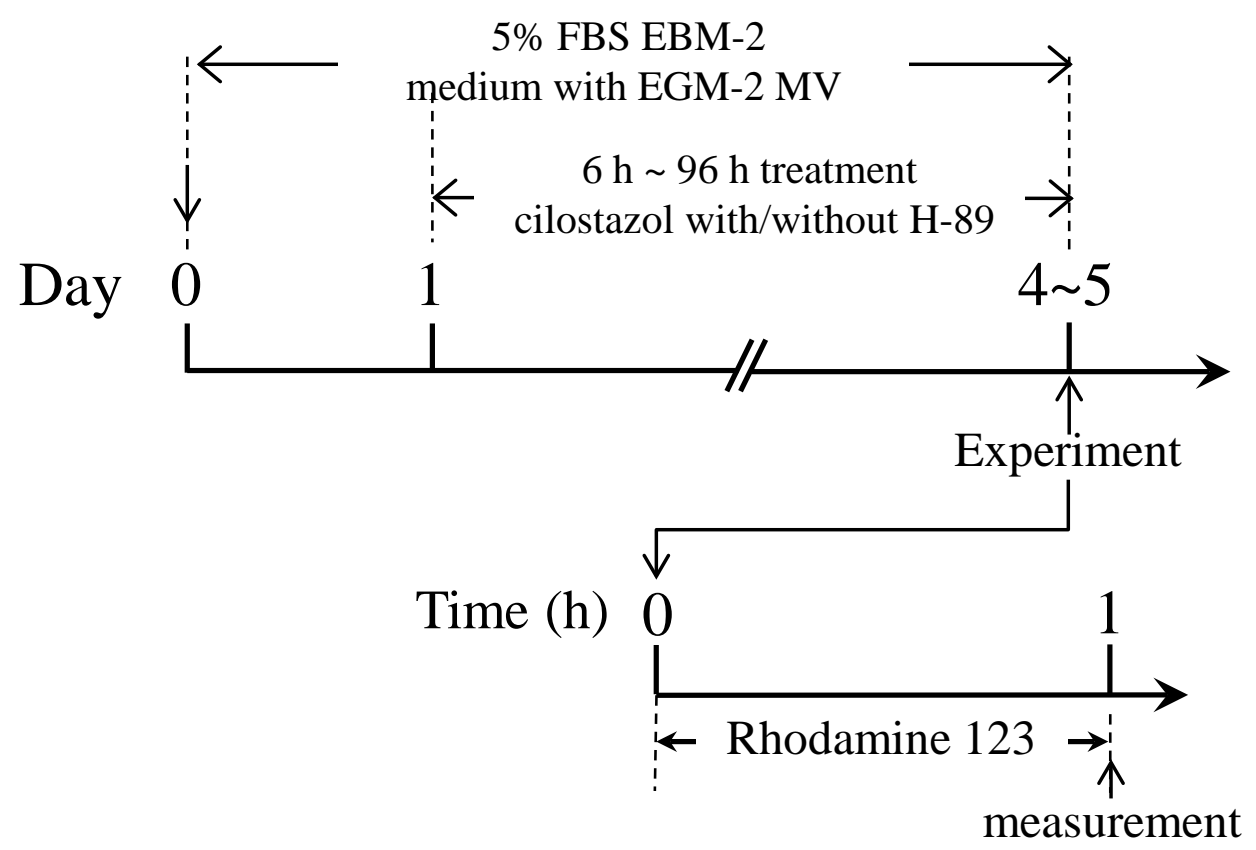


Fig. 2

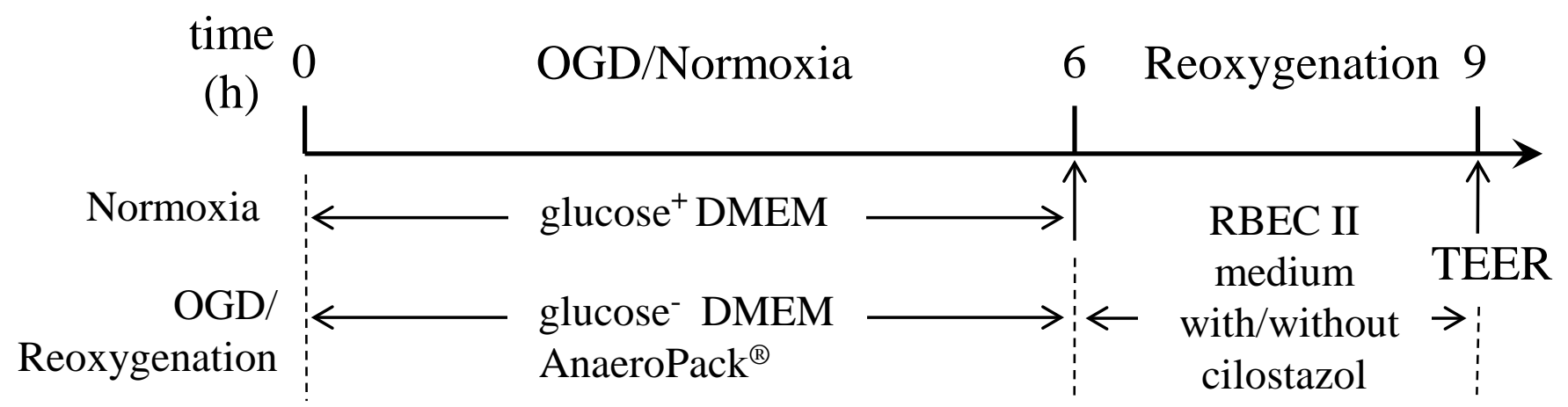


Fig. 3

A

\section{PDE3A PDE3B}

506 bp
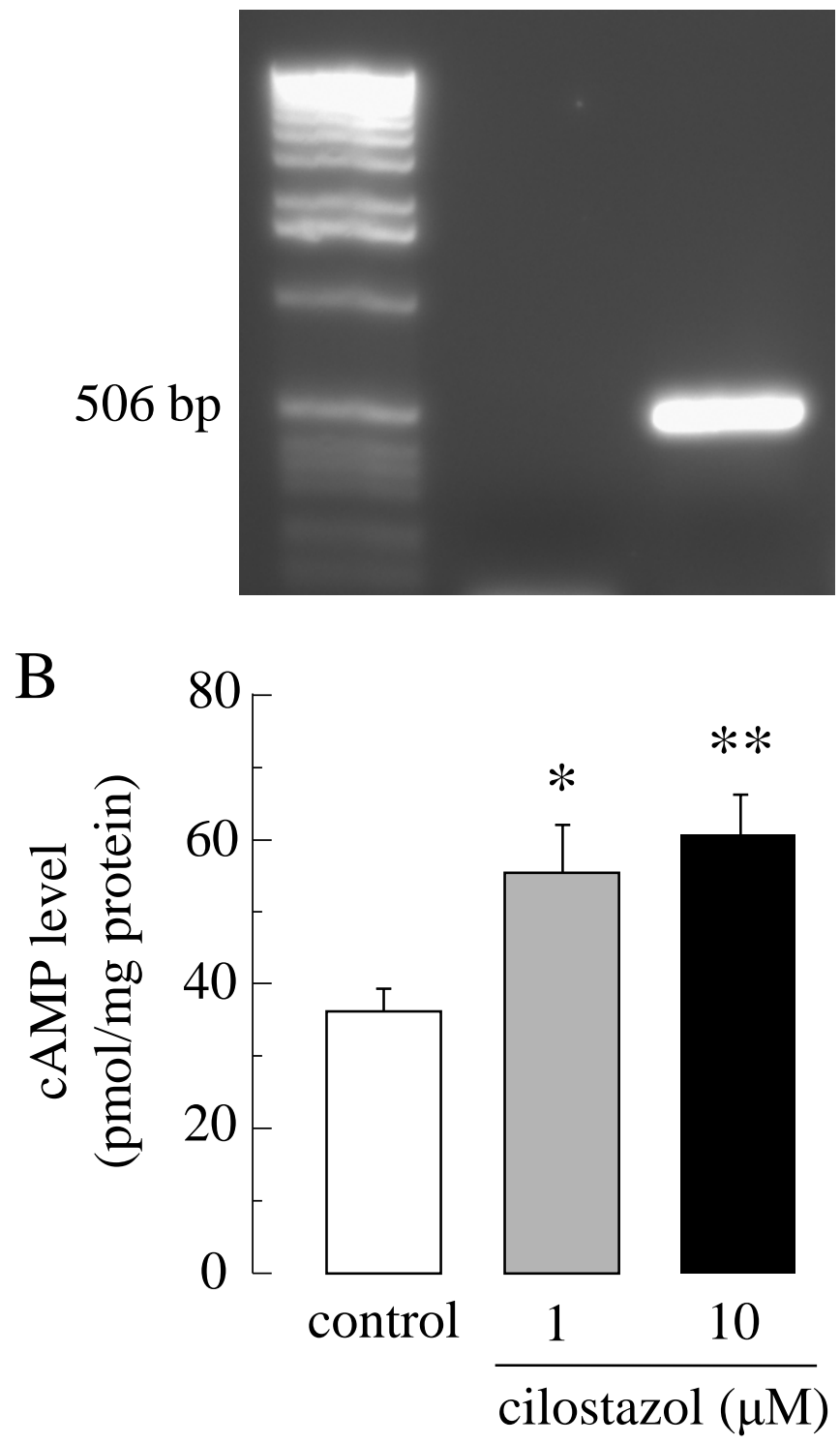
Fig. 4

A
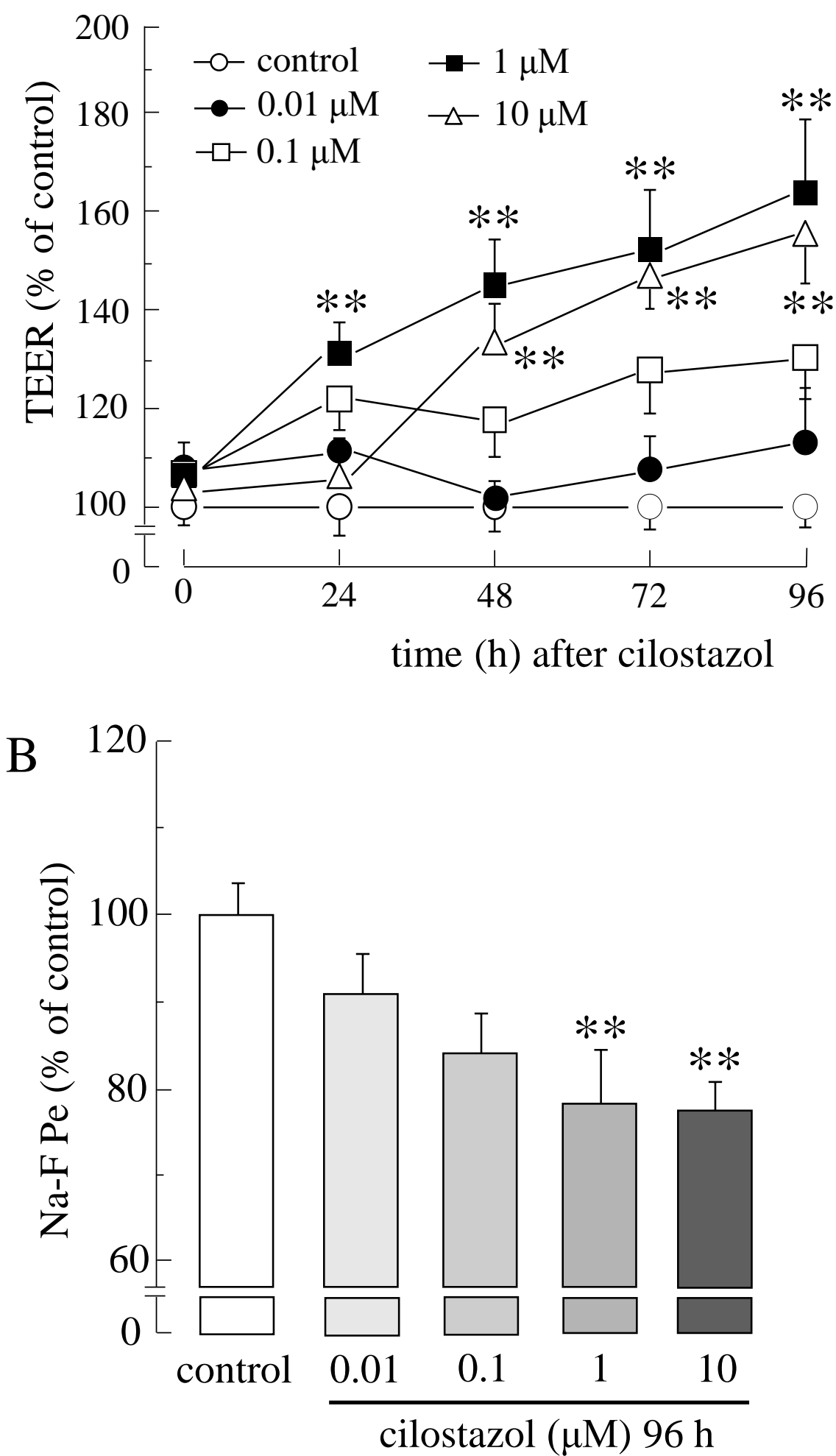
Fig. 5

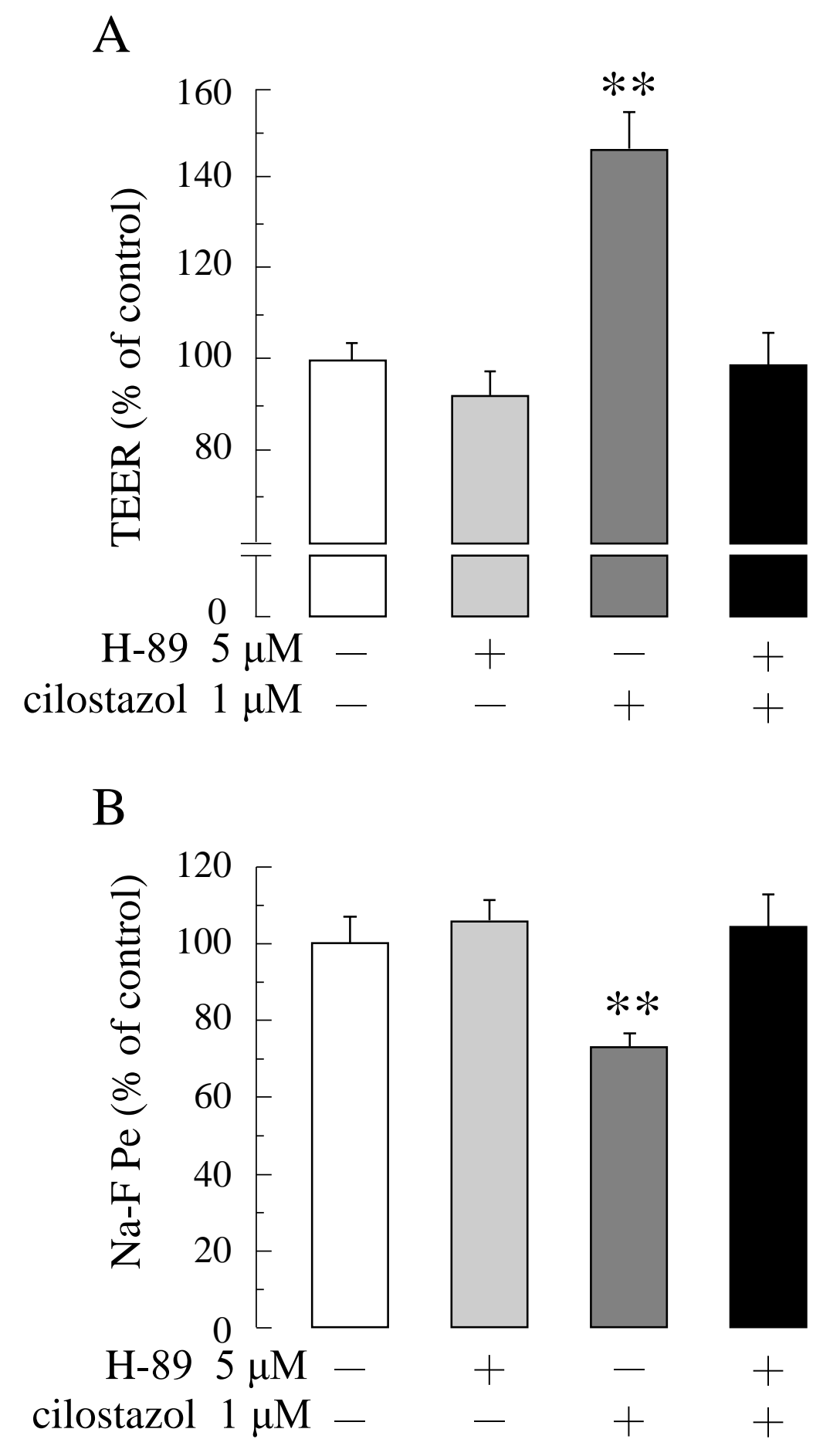


Fig. 6

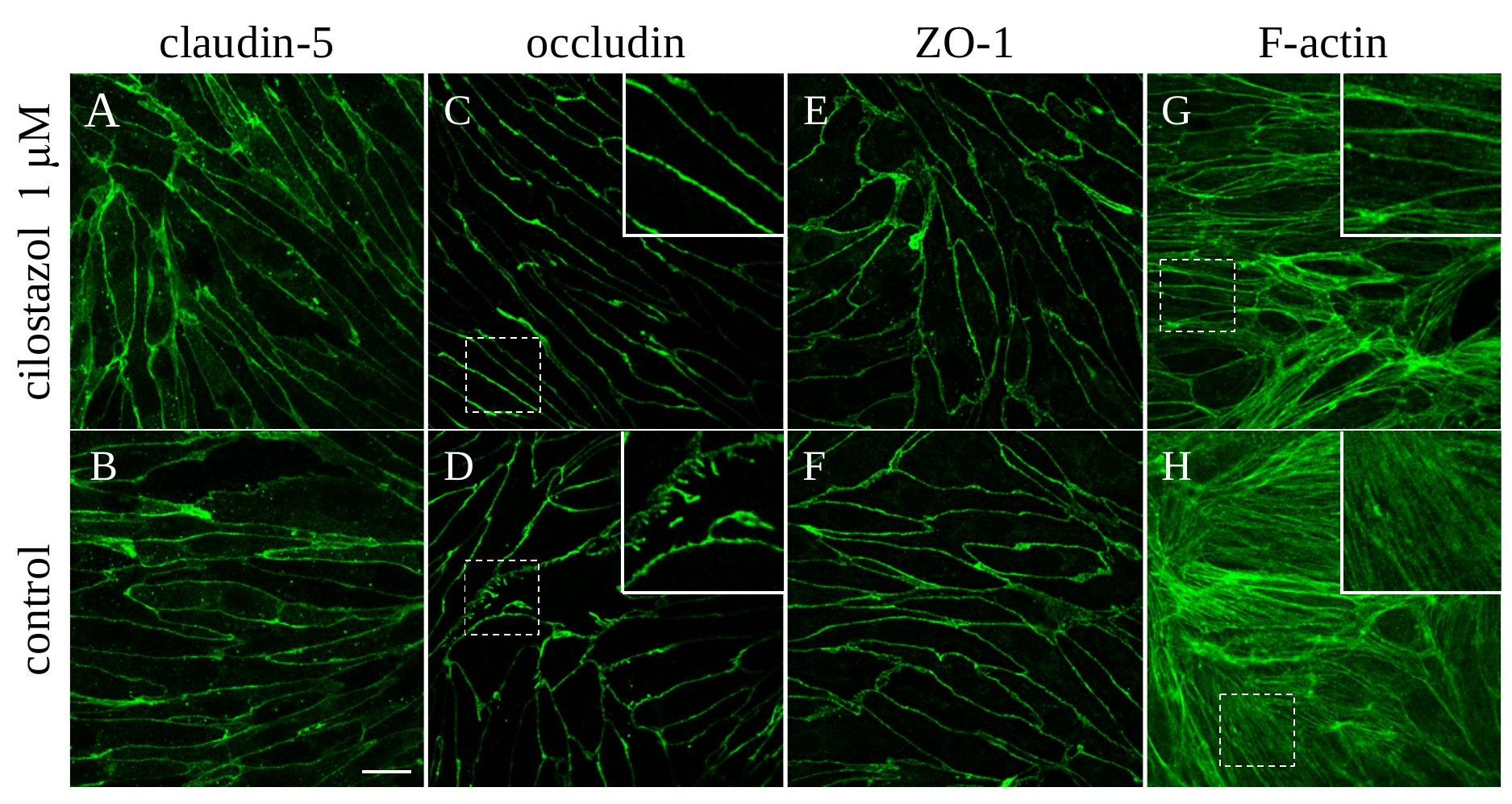


Fig. 7

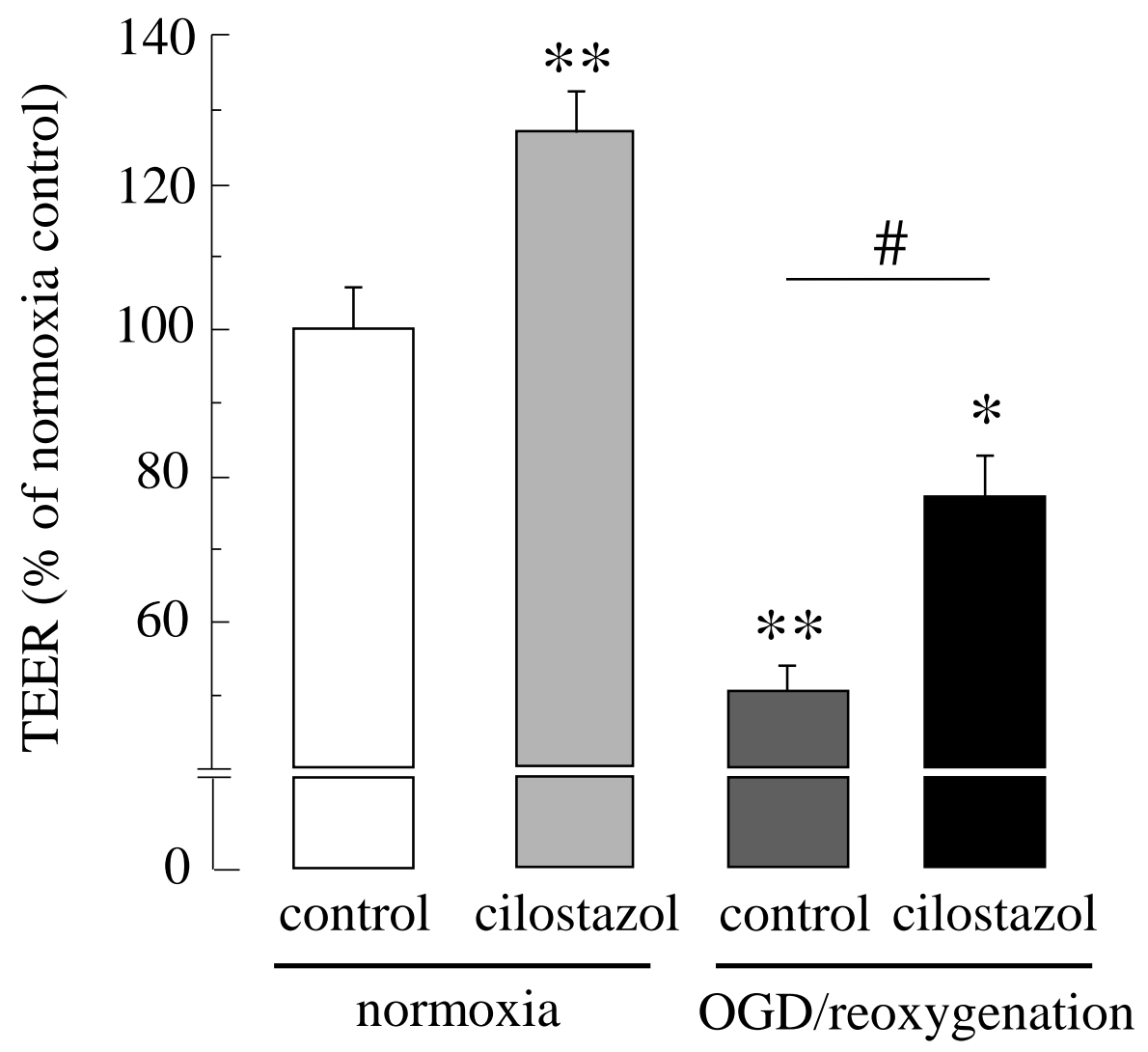


Fig. 8

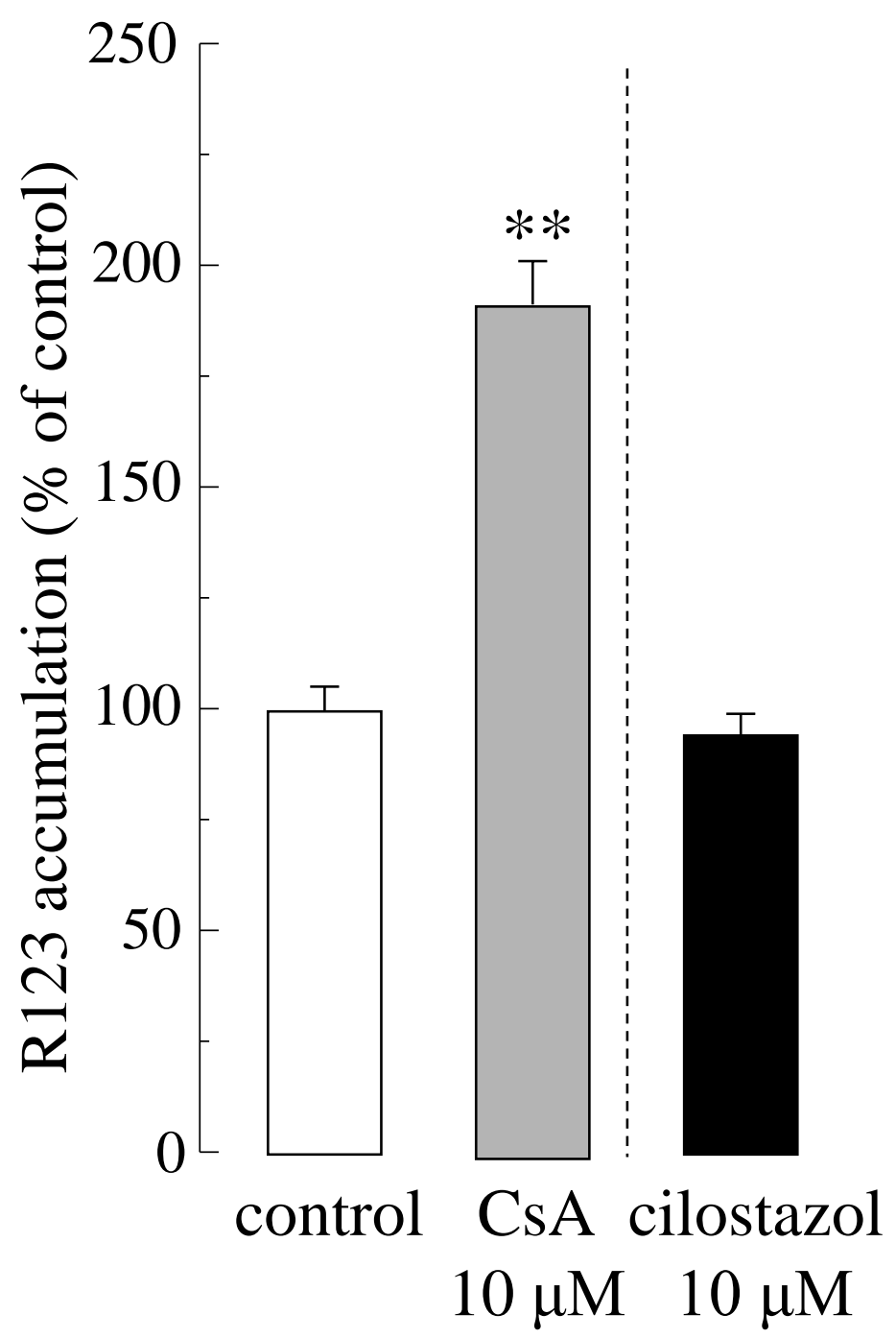


Fig. 9
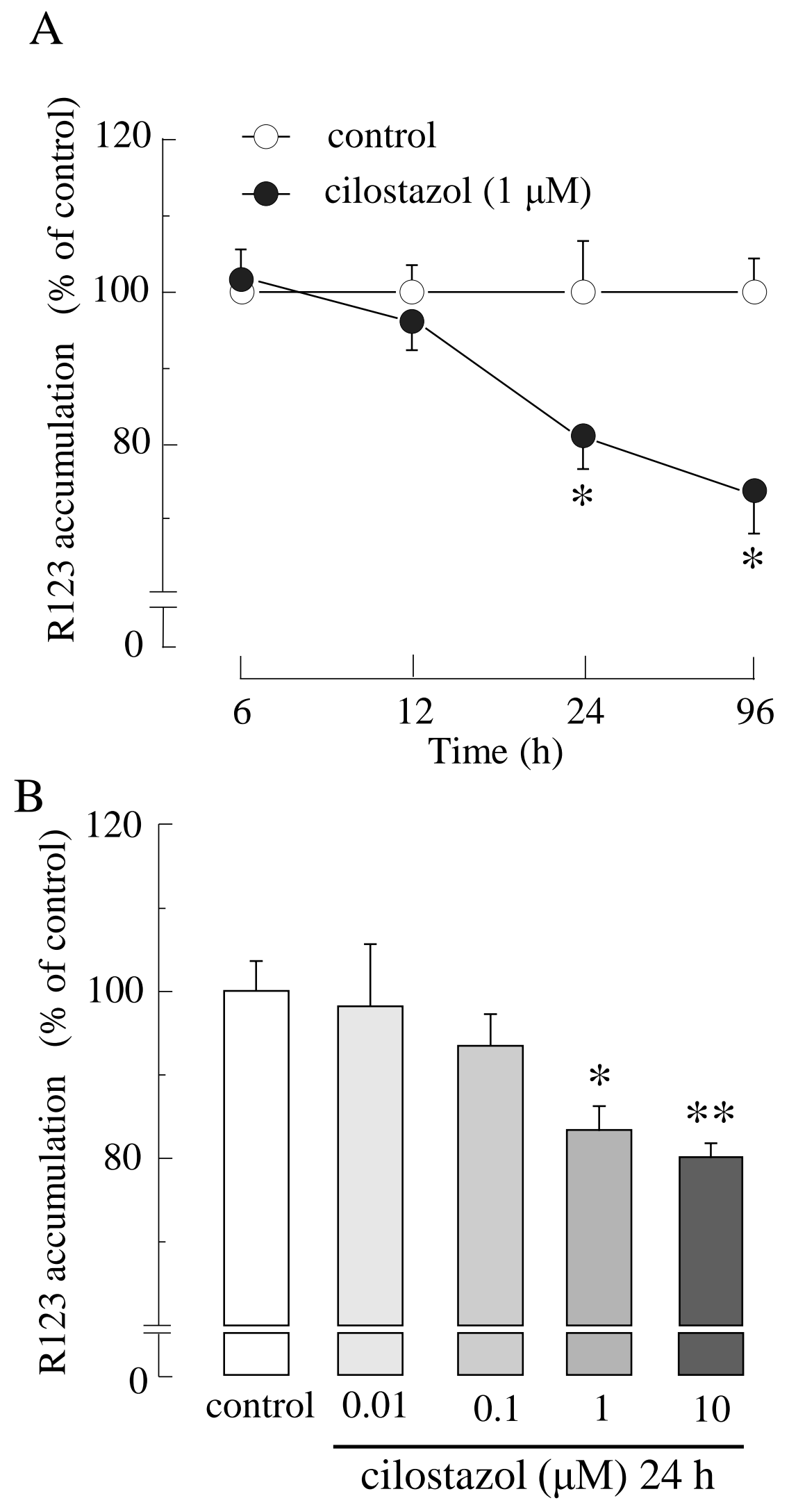
Fig. 10

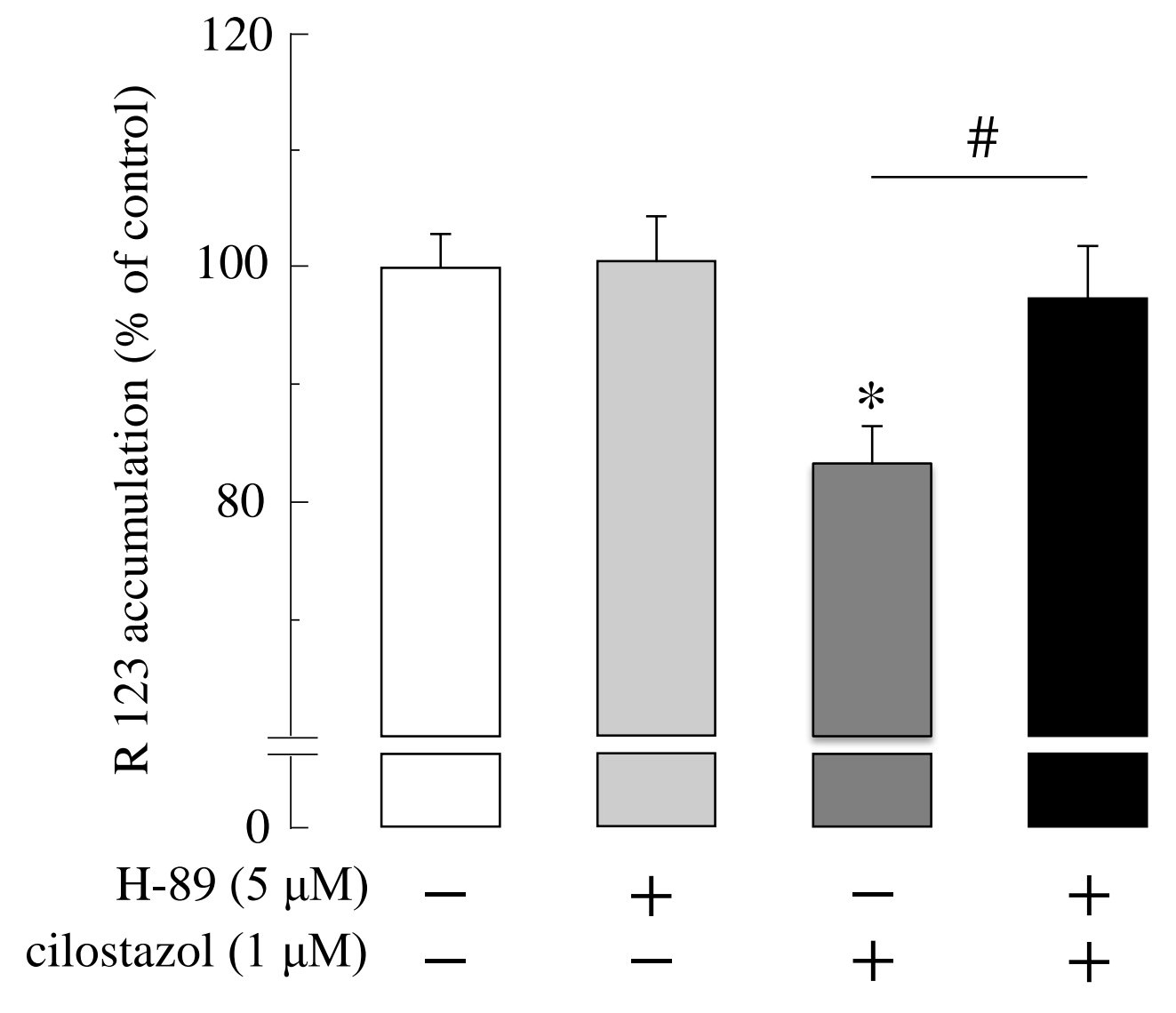

